\title{
Prevalence of microalbuminuria and associated risk factors among adult Korean hypertensive patients in a primary care setting
}

\author{
Yon Su Kim ${ }^{1}$, Han Soo Kim², Ha Young $\mathrm{Oh}^{3}$, Moon-Kyu Lee ${ }^{4}$, Cheol Ho Kim ${ }^{5}$, Yong Soo Kim ${ }^{6}$, David Wu ${ }^{6}$, \\ Amy O Johnson-Levonas ${ }^{6}$ and Byung-Hee $\mathrm{Oh}^{7}$
}

Microalbuminuria is an early sign of nephropathy and an independent predictor of end-stage renal disease. The purpose of this study was to assess microalbuminuria prevalence and its contributing factors in Korean hypertensive patients. This cross-sectional study enrolled male and female patients of $\geqslant 35$ years old with an essential hypertension diagnosis as made by 841 physicians in primary care clinics and 17 in general hospitals in the Republic of Korea between November 2008 and July 2009. To assess microalbuminuria prevalence, urine albumin/creatinine ratio (UACR) was measured in patients with a positive dipstick test. Of the 40473 enrolled patients, $5713(14.1 \%)$ had a positive dipstick test. Of 5393 patients with a positive dipstick test and valid UACR values, $2657(6.6 \%)$ had significantly elevated UACR ( $\geqslant 30 \mu \mathrm{g} \mathrm{mg}^{-1}$ ), $2158(5.4 \%)$ had microalbuminuria $\left(30 \mu \mathrm{g} \mathrm{mg}^{-1} \leqslant\right.$ UACR $\left.<300 \mu \mathrm{gg}^{-1}\right)$ and $499(1.2 \%)$ had macroalbuminuria (UACR $\geqslant 300 \mu \mathrm{g} \mathrm{mg}^{-1}$ ). Based on multivariate analysis, independent factors associated with elevated UACR included low adherence to antihypertensive medication (23\% higher; $\boldsymbol{P}=\mathbf{0 . 0 4 2}$ ), poorly controlled blood pressure (BP; $38 \%$ higher for systolic BP/diastolic BP $\geqslant 130 \mathrm{~mm} \mathrm{Hg} / \geqslant 80 \mathrm{~mm} \mathrm{Hg} ; P<0.001$ ), obesity (47\% higher for body mass index (BMI) $\geqslant 25.0 \mathrm{~kg} \mathrm{~m}^{-2} ; P<0.001$ ), age (17\% lower and 58\% higher for age categories $35-44$ years $(P=0.043)$ and $>75$ years $(P<0.001)$, respectively) and a prior history of diabetes $(151 \%$ higher; $\boldsymbol{P}<0.001)$ and kidney-related disease $(71 \%$ higher; $\boldsymbol{P}<0.001)$. The prevalences of elevated UACR and microalbuminuria were $6.6 \%$ and $5.4 \%$, respectively. Age, increased BMI, presence of comorbidities, poor medication adherence and inadequately controlled BP were independent predictors of elevated UACR after controlling for potential confounders.

Hypertension Research (2013) 36, 807-823; doi:10.1038/hr.2013.44; published online 23 May 2013

Keywords: hypertension; Korean; microalbuminuria; prevalence; primary care

\section{INTRODUCTION}

The excretion of small, subclinical amounts of albumin in the urine is a condition known as microalbuminuria. ${ }^{1}$ Initially, this condition was found to be a predictor of future progression of renal disease in patients with diabetic nephropathy. ${ }^{2,3}$ However, the presence of microalbuminuria has since been associated with higher cardiovascular risk and end-stage renal disease in patients with other conditions (for example, hypertension) ${ }^{4-6}$ as well as in the general population. ${ }^{7,8}$ Microalbuminuria is defined as a urinary albumin/creatinine ratio (UACR) higher than the threshold value obtained from studies assessing the risk for developing nephropathy in diabetes patients (that is, between 20 and $200 \mu \mathrm{g} \mathrm{min}-1$ or $\geqslant 30$ to $<300 \mathrm{mg}$ per day). ${ }^{9,10}$
Hypertension is one of the most important risk factors for cardiovascular disease. ${ }^{11}$ The association of hypertension with elevated levels of urinary albumin excretion is well established. ${ }^{12-14}$ The incidence of microalbuminuria is more common among hypertensive patients, even in nondiabetic patients. ${ }^{15}$ Several epidemiologic studies also have shown that the presence of proteinuria or microalbuminuria is an independent predictor of cardiovascular morbidity and mortality in patients with essential hypertension. ${ }^{16-20}$ Therefore, current guidelines recommend routine screening of microalbuminuria in hypertensive patients to ensure appropriate interventions are initiated early in the disease process before progression to chronic kidney disease and/or renal failure. $^{10}$

\footnotetext{
${ }^{1}$ Division of Nephrology, Department of Internal Medicine, Seoul National University College of Medicine, Seoul, Korea; ${ }^{2}$ Division of Cardiology, 21 st Century Clinic, Seoul, Korea; ${ }^{3}$ Division of Nephrology, Department of Medicine, Samsung Medical Center, Sungkyunkwan University School of Medicine, Seoul, Korea; ${ }^{4}$ Division of Endocrinology, Department of Medicine, Samsung Medical Center, Sungkyunkwan University School of Medicine, Seoul, Korea; ${ }^{5}$ Division of Cardiology, Seoul National University College of Medicine, Bundang Seoul National University Hospital, Seoul, Korea; ${ }^{6}$ Merck Sharp \& Dohme Corp., Whitehouse Station, NJ, USA and ${ }^{7}$ Department of Internal Medicine, Seoul National University College of Medicine, Seoul, Korea

Correspondence: Professor B-H Oh, Department of Internal Medicine, Seoul National University College of Medicine, 101 Daehak-ro, Seoul 110-744, Korea.

E-mail: ohbhmed@snu.ac.kr
}

Received 23 August 2012; revised 13 February 2013; accepted 14 February 2013; published online 23 May 2013 
Screening programs for high-risk patients with diabetes and/or hypertension represent excellent opportunities for prevention and early treatment of albuminuria. Such screening programs are important in Asian countries because of the increasing incidence of diabetes and hypertension seen in this region. ${ }^{1,21,22}$ Asian patients with diabetes have the highest incidence of albuminuria, accounting for roughly $55 \%$ of all cases worldwide. ${ }^{23}$ In the Asia Pacific region, microalbuminuria prevalence is estimated to range between 10.0 and $13.7 \%$ among hypertensive patients, ${ }^{7,8,24} 15.0$ and $20.3 \%$ in diabetic patients $^{25-27}$ and 22.2 and $48.5 \%$ in diabetic hypertensive patients. ${ }^{25,28-35}$ Microalbuminuria can be decreased by as much as $44 \%$ using hypertension interventions in Asian populations, thus highlighting the need for adequate blood pressure (BP) control in such patients. ${ }^{27,36,37}$

Large ethnic/racial variations in the prevalence of microalbuminuria among hypertensive patients have been documented. Two recently published large-scale population-based surveys, the NHANES III (US National Health and Nutrition Examination Survey) and the PREVEND (Prevention of Renal and Vascular End-Stage Disease study), reported microalbuminuria prevalences of 16 and $11.5 \%$ among people with hypertension in the United States and Europe (that is, the Netherlands). ${ }^{38,39}$ In the I-DEMAND (Italy Developing Education and awareness on Microalbuminuria in patients with hyperteNsive Disease) study, microalbuminuria was observed in $27 \%$ of the overall population. ${ }^{40}$ An international, observational study, i-SEARCH (Survey for Evaluating Microalbuminuria Routinely by Cardiologists conducted in patients with Hypertension), demonstrated a very high worldwide prevalence (58.4\%) of microalbuminuria in high-risk cardiovascular patients with hypertension. ${ }^{41}$ More recently, a lower frequency of microalbuminuria $(22.7 \%)$ was observed in the REDHY (Renal Dysfunction in Hypertension) study conducted in patients with hypertension without cardiovascular complications and known renal disease. ${ }^{42,43}$ Reported differences in prevalence rates among studies may be due to the differences in the number of patients studied, severity of hypertension, average age of the study populations, racial/ethnic differences, coexistence of comorbid diseases in the study populations (for example, diabetes and renal insufficiency) and study methodologies.

Although it is well known that the frequency of microalbuminuria differs widely across ethnic/racial populations, few studies have evaluated the prevalence of microalbuminuria specifically in Korean hypertensive patients. Three prior cross-sectional studies conducted in Koreans reported prevalence rates ranging from 2.8 to $12 \%$ in healthy, non-diabetic patients, ${ }^{7,44} 10.1 \%$ in hypertensive patients without diabetes, ${ }^{7} 16.1 \%$ in patients with type 2 diabetes $^{7}$ and $23.1 \%$ in patients with hypertension and type 2 diabetes. ${ }^{45}$ Reasons for the wide variability in microalbuminuria rates observed in Koreans are unknown but may be due in part to differences in the UACR criteria and methodologies employed to define and identify microalbuminuria, the small number of patients enrolled in these studies (study N's ranged from 497 to 7569 ) and differences in the patient populations (for example, preferential enrollment of patients from rural areas vs nationwide enrollment). The purpose of this large, cross-sectional study was to provide a more definitive assessment of the prevalence of microalbuminuria among Koreans diagnosed with primary/essential hypertension. This study surveyed people receiving treatment in a primary care setting to allow for a more representative sample of the overall population of hypertensive patients living in the Republic of Korea. Furthermore, the detection of microalbuminuria was based on an antibody-based dipstick screening test with subsequent confirmation via measurement of UACR to definitively identify patients with microalbuminuria. The specific objectives of this study were as follows: (1) determine the prevalence of albuminuria as assessed by a positive dipstick test alone; (2) determine prevalence of microalbuminuria as assessed by a positive dipstick test and a valid UACR value (that is, $\geqslant 30$ to $<300 \mu \mathrm{g} \mathrm{mg}^{-1}$ ); (3) evaluate the clinical and demographic characteristics associated with albuminuria and microalbuminuria in Korean hypertensive patients.

\section{MATERIALS AND METHODS}

\section{Study population}

This cross-sectional study was performed from November 2008 to July 2009 by 858 physicians practicing in general medical clinics (for example, primary care physician, family medicine or outpatient primary care clinic in hospitals) in the Republic of Korea. A total of 777 general medical clinics and 4 general hospitals enrolled 40604 patients. The study was conducted in accordance with principles of Good Clinical Practice, and the study protocol was reviewed and approved by the appropriate Institutional Review Board (IRB; Cheju Halla General Hospital IRB, Special Self-Governing Province, Korea; Bong Seng Memorial Hospital IRB, Busan, Korea; Daedong Hospital IRB, Busan, Korea; Keimyung University Dongsan Medical Center IRB, Daegu, Korea). Each physician screened an average of 50 patients to determine study eligibility and each enrolled 1-113 patients. All patients provided written informed consent form at the time of enrollment.

The major inclusion criteria were age $\geqslant 35$ years, diagnosis of primary/ essential hypertension (that is, defined as BP $>140 / 90 \mathrm{~mm} \mathrm{Hg}$ in patients not previously diagnosed with hypertension or in patients with a previous diagnosis of hypertension and reported current use of antihypertensive medications) and ability to understand and complete the patient questionnaire in Korean. Patients were excluded from the study if they had secondary hypertension, were involved in another interventional clinical study or were incapable of completing the questionnaire in Korean. Patients were allowed to take any medication deemed necessary by their prescribing physician throughout the course of this study.

\section{Data collection and evaluation}

During each clinic visit, physicians assessed the patients' hypertension status, medication use and BP. The physician also provided information regarding patient comorbidities, laboratory data for assessing coronary heart disease (CHD) risk (for example, lipids and lipoprotein values) and duration of hypertension. In addition, patients were required to fill out a questionnaire for collecting information on demographics, lifestyle, current medical illness (age at hypertension diagnosis, diabetes status, history of stroke, kidney problems, heart attack/myocardial infarction, other heart problems, heart-related surgery), family history of CHD and medication adherence.

At enrollment, all eligible patients had BP measured in duplicate by a standard mercury sphygmomanometer at 2-min intervals using the right arm after the patient had assumed a seated position for at least $5 \mathrm{~min}$. Caffeine was not allowed for at least $1 \mathrm{~h}$ and smoking was not allowed for at least $30 \mathrm{~min}$ before the BP measurement. Venous blood samples $(5 \mathrm{ml})$ for measurement of plasma lipids were collected after an 8-h fast.

Attainment of the hypertension goal was determined using the cutoff value of $<130 / 80 \mathrm{mmHg}$ in patients with and without compelling complications such as diabetes, high CHD risk, prior history of a CHD event as assessed from information obtained in the physician and participant questionnaires. $^{45}$

\section{Urinary albumin measurements}

At the screening visit, all patients provided spot urine samples for evaluation of albuminuria using an antibody-based dipstick test. The dipstick test was similar to Micral (Roche Diagnostics, Mannheim, Germany), which has been shown to detect urinary albumin concentrations $\geqslant 20 \mathrm{mgl}^{-1} .46$ At the threshold of $\geqslant 20 \mathrm{mgl}^{-1}$, this test has been found to be $95 \%$ sensitive (confidence interval (CI): 90-99\%) and >80\% specific (CI: 70-90\%). Patients were classified as either negative (that is, normal) or positive (that is, 
Table 1 Baseline demographic characteristics of enrolled patients both in the overall population and broken down by dipstick test status

\begin{tabular}{|c|c|c|c|}
\hline Characteristics & $\begin{array}{c}\text { All patients } \\
(\mathrm{N}=40153)\end{array}$ & $\begin{array}{c}\text { Patients with negative } \\
\text { Micral test }(\mathrm{N}=34760)\end{array}$ & $\begin{array}{l}\text { Patients with positiv } \\
\text { Micral test }{ }^{a}(\mathrm{~N}=539\end{array}$ \\
\hline \multicolumn{4}{|l|}{ Clinical Characteristics } \\
\hline Age, years, mean \pm s.d. & $58.5 \pm 10.2$ & $58.4 \pm 10.1$ & $59.4 \pm 10.3^{* *}$ \\
\hline \multicolumn{4}{|l|}{ Age category, years, $N(\%)$} \\
\hline $35-44$ & $3269(8.1)$ & $2900(8.3)$ & $369(6.8)^{* *}$ \\
\hline $45-54$ & $11498(28.6)$ & $10006(28.8)$ & $1492(27.7)$ \\
\hline $55-64$ & $13533(33.7)$ & $11750(33.8)$ & $1783(33.1)$ \\
\hline $65-74$ & $9354(23.3)$ & $8009(23.0)$ & $1345(24.9)$ \\
\hline$\geqslant 75$ & $2499(6.2)$ & $2095(6.0)$ & $404(7.5)$ \\
\hline \multicolumn{4}{|l|}{ Gender, N (\%) } \\
\hline Male & $19686(49.0)$ & $16914(48.7)$ & $2772(51.4)^{* *}$ \\
\hline Female & $20462(51.0)$ & $17843(51.3)$ & 2619 (48.6) \\
\hline Missing & $5(0.0)$ & $3(0.0)$ & $2(0.0)$ \\
\hline Height, $\mathrm{cm}$, mean \pm s.d. & $163.1 \pm 8.8$ & $163.2 \pm 8.8$ & $162.7 \pm 8.5^{* *}$ \\
\hline Weight, kg, mean \pm s.d. & $65.5 \pm 10.4$ & $65.3 \pm 10.4$ & $66.7 \pm 10.7^{* *}$ \\
\hline BMI, $\mathrm{kg} \mathrm{m}^{-2}$, mean \pm s.d. & $24.6 \pm 2.9$ & $24.5 \pm 2.8$ & $25.1 \pm 3.1^{* *}$ \\
\hline \multicolumn{4}{|l|}{ BMI category, $\mathrm{kgm}^{-2}, \mathrm{~N}(\%)$} \\
\hline Underweight $(<18.5)$ & $450(1.1)$ & $413(1.2)$ & $37(0.7)$ \\
\hline Normal (18.5-22.9) & $11236(28.0)$ & $10023(28.8)$ & $1213(22.5)^{* *}$ \\
\hline Overweight (23.0-24.9) & $12102(30.1)$ & $10518(30.3)$ & $1584(29.4)$ \\
\hline Obese $(\geqslant 25.0)$ & $16365(40.8)$ & $13806(39.7)$ & 2559 (47.5) \\
\hline \multicolumn{4}{|l|}{ Smoking status, N (\%) } \\
\hline Never & $23800(59.3)$ & $20587(59.2)$ & $3213(59.6)$ \\
\hline Former (quit > 1 month) & 7194 (17.9) & $6260(18.0)$ & $934(17.3)$ \\
\hline Current & 7994 (19.9) & $6891(19.8)$ & $1103(20.5)$ \\
\hline Unknown & $1165(2.9)$ & $1022(2.9)$ & $143(27.5)$ \\
\hline Alcohol consumption frequency, mean \pm s.d. & $0.9 \pm 1.4$ & $0.9 \pm 1.3$ & $1.1 \pm 1.5^{* *}$ \\
\hline \multicolumn{4}{|l|}{ Alcohol consumption category, $\mathrm{N}(\%)$} \\
\hline 4-6 Times per week & $2028(5.1)$ & $1642(4.7)$ & $386(7.2)^{* *}$ \\
\hline 2-3 Times per week & $5557(13.8)$ & $4738(13.6)$ & $819(15.2)$ \\
\hline Once per week & $4387(10.9)$ & $3856(11.1)$ & $531(9.9)$ \\
\hline 1-3 Times per month & $3812(9.5)$ & $3330(9.6)$ & $482(8.9)$ \\
\hline Less than once per month & $2783(6.9)$ & $2389(6.9)$ & $394(7.3)$ \\
\hline I do not drink alcohol & $15046(37.5)$ & $13086(37.7)$ & $1960(36.3)$ \\
\hline I do not know & $1179(2.9)$ & $1027(3.0)$ & $152(2.8)$ \\
\hline Not applicable & $5361(13.4)$ & $4692(13.5)$ & $669(12.4)$ \\
\hline Duration of hypertension, years, mean \pm s.d. & $6.1 \pm 5.0$ & $6.0 \pm 4.9$ & $6.9 \pm 5.6^{* *}$ \\
\hline \multicolumn{4}{|l|}{ Duration of hypertension category, years, N (\%) } \\
\hline$<1$ & $84(0.2)$ & $65(0.2)$ & $19(0.4)^{* *}$ \\
\hline $1-5$ & $23975(59.7)$ & $21131(60.8)$ & $2844(52.7)$ \\
\hline $6-10$ & $11421(28.4)$ & $9750(28.1)$ & $1671(31.0)$ \\
\hline $11-20$ & $3191(8.0)$ & $2626(7.6)$ & $565(10.5)$ \\
\hline$\geqslant 21$ & $1452(3.6)$ & $1162(3.3)$ & $290(5.4)$ \\
\hline Missing & $30(0.1)$ & $26(0.1)$ & $4(0.1)$ \\
\hline $\mathrm{SBP}, \mathrm{mm} \mathrm{Hg}$, mean \pm s.d. & $130.2 \pm 11.0$ & $130.1 \pm 10.8$ & $131.0 \pm 12.2^{* *}$ \\
\hline $\mathrm{DBP}, \mathrm{mm} \mathrm{Hg}$, mean \pm s.d. & $81.8 \pm 7.7$ & $81.7 \pm 7.7$ & $82.2 \pm 8.0^{* *}$ \\
\hline \multicolumn{4}{|l|}{ Blood pressure control, N (\%) } \\
\hline $\mathrm{SBP}<130 \mathrm{~mm} \mathrm{Hg}$ and DBP $<80 \mathrm{~mm} \mathrm{Hg}$ & $6613(16.5)$ & $5778(16.6)$ & $835(15.5)^{*}$ \\
\hline $\mathrm{SBP} \geqslant 130 \mathrm{~mm} \mathrm{Hg}$ and/or DBP $\geqslant 80 \mathrm{~mm} \mathrm{Hg}$ & $33540(83.5)$ & $28982(83.4)$ & $4558(84.5)$ \\
\hline \multicolumn{4}{|l|}{ Currently prescribed antihypertensive medications } \\
\hline ARB (or associated fixed dose combo) & $26685(66.5)$ & $23113(66.5)$ & $3572(66.2)$ \\
\hline ACEI (or associated fixed dose combo) & $3264(8.1)$ & $2860(8.2)$ & $404(7.5)$ \\
\hline$\beta$-Blockers & $5785(14.4)$ & $4960(14.3)$ & $825(15.3)^{*}$ \\
\hline
\end{tabular}


Table 1 (Continued)

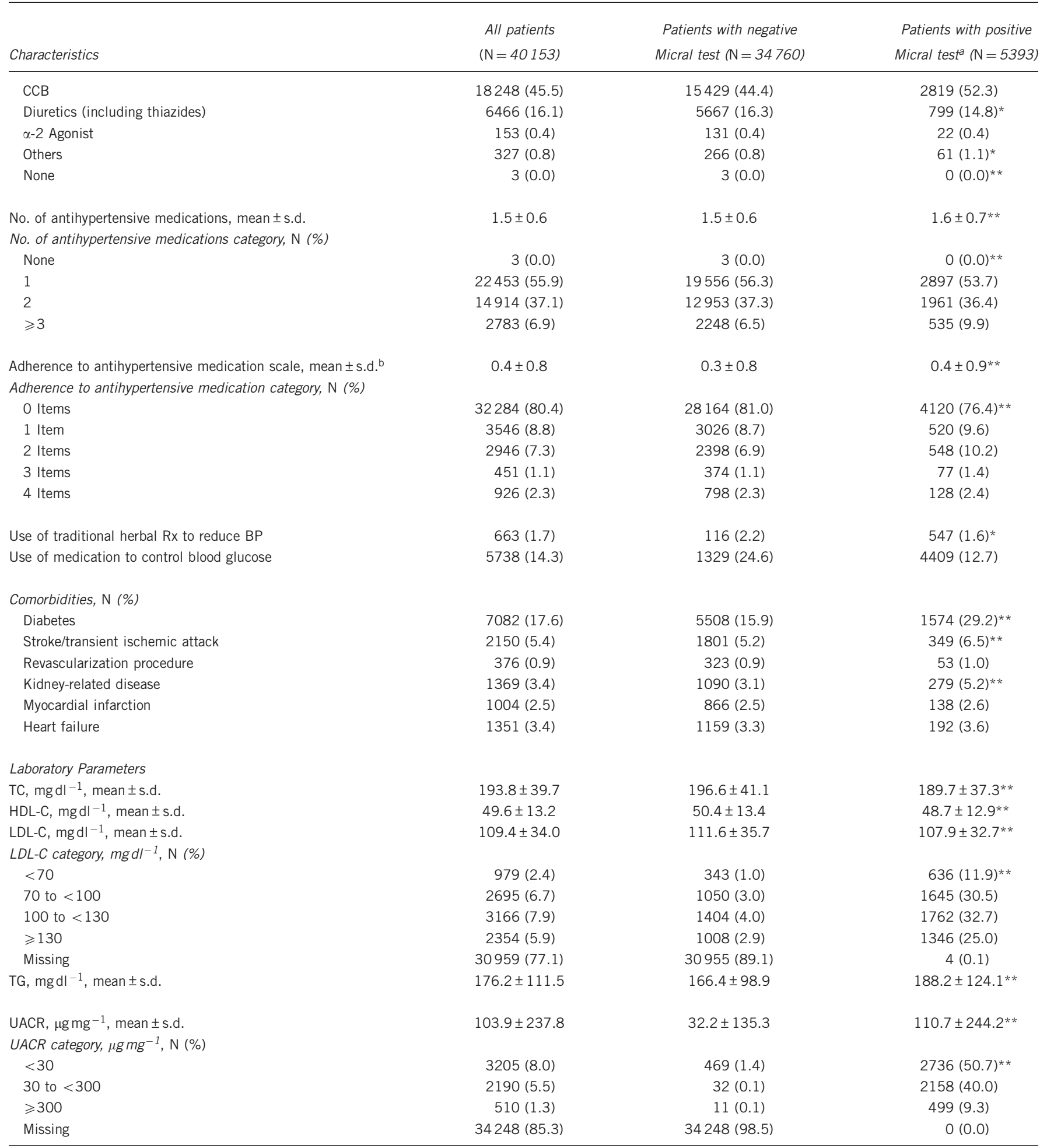

Abbreviations: ACEI, angiotensin converting enzyme inhibitor; ARB, angiotensin II receptor blocker; BMI, body mass index; CCB, calcium channel blocker; DBP, diastolic blood pressure; HDL-C, high-density lipoprotein cholesterol; LDL-C, low-density lipoprotein cholesterol; SBP, systolic blood pressure; TC, total cholesterol; TG, triglycerides; UACR, urine albumin/creatinine ratio. All values are shown as mean \pm s.d. or $n(\%)$ of patients.

${ }^{*} P<0.05 ;{ }^{* *} P<0.001$ represents the significance of differences in distribution of variables/values between patients with positive and negative Micral tests and is estimated after excluding patients with the missing values.

patients with the missing values.
aPatients with positive Micral test $=$ patients with positive dipstick test and valid UACR value.

bHigh medication adherence scores indicate poor adherence to medication based on the range of $0-4(0=$ high, $1-2=$ medium, 3-4 =low adherence). 


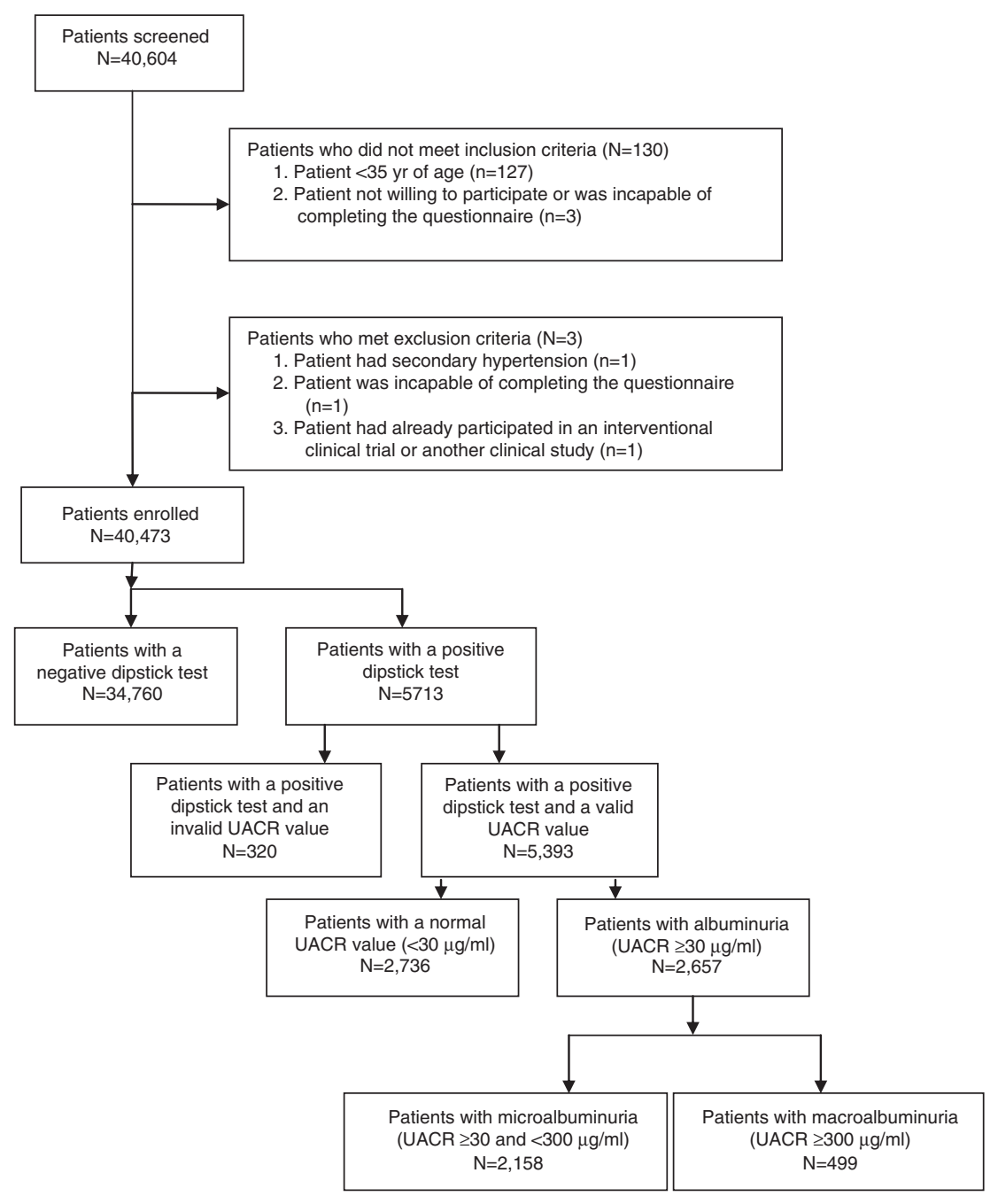

$\mathrm{UACR}=$ urinary albumin creatinine ratio

Figure 1 Disposition of patients in study.

at least $20 \mathrm{mgl}^{-1}$ ) on the dipstick testing. Urine samples collected from patients with a positive dipstick test were sent to a central laboratory (Green Cross Reference Laboratory, Kyunggi-do, Korea) for a more quantitative measurement of UACR as assessed by the immunoturbidimetric technique (Microalbumin Analyzer: ADVIA 1650 Analyzer, Bayer Diagnostics, Tarrytown, NY, USA). Patients were classified into normal (that is, UACR $<30 \mu \mathrm{g} \mathrm{mg}^{-1}$ ), microalbuminuria (that is, UACR $\geqslant 30$ to $<300 \mu \mathrm{g} \mathrm{mg}^{-1}$ ) or macroalbuminuria/proteinuria (that is, $\geqslant 300 \mu \mathrm{g} \mathrm{mg}^{-1}$ ) based on a single UACR value.

\section{Statistical analyses}

The overall analysis population $(N=40153$; that is, after excluding 320 patients with invalid UACR values) was prespecified to include patients with negative dipstick $(n=34760)$ or positive dipstick tests and valid UACR values $(n=5393)$. The prevalences of microalbuminuria (UACR $\geqslant 30$ to $<300 \mu \mathrm{g} \mathrm{mg}^{-1}$ ) in the overall study population and within subject subgroups were estimated. Patients had to have a positive dipstick test and a valid UACR value to be included in the analysis of albuminuria. Categorical variables were summarized using frequency and percentages. Continuous variables were summarized using mean \pm standard deviation (s.d.) unless otherwise indicated. The prevalence of albuminuria was calculated by stratifying patients based on demographic parameters, clinical characteristics, use of antihypertensive medication and comorbidities (Table 1). Differences in continuous variables were tested using Student's $t$-test, and differences in categorical variables were tested using $\chi^{2}$ or Fisher's exact test.

\section{Factors associated with the presence of albuminuria}

The relationship between albuminuria and various factors (that is, covariates) were assessed using logistic regression analyses. A univariate logistic regression model estimated the crude, unadjusted odds ratios (ORs) and 95\% CIs for the presence of albuminuria. A multiple logistic regression model was then used to estimate the OR and $95 \%$ CI for the presence of albuminuria after adjusting for confounding factors, including patient demographics, clinical characteristics, use of medication and comorbid conditions. Low-density lipoprotein cholesterol (LDL-C) values and physical activity were not included in this model, because of the large number of missing data for these parameters. The independent variables in logistic regression models were selected using forward stepwise regression with 0.2 of significant value for staying in the model. $P$-values were two sided, and $P<0.050$ was considered to indicate statistical significance. All analyses were performed using System Analysis System Software Version 8.2 (SAS Institute, Cary, NC, USA).

\section{RESULTS}

A total of 858 physicians agreed to participate in this study, with each physician enrolling approximately 47 patients on average. The 
majority of physicians were from the Seoul region (49.3\%) of Korea. The overall disposition of patients in this study is shown in Figure 1. In total, 40604 patients were screened for study entry, of which 40473 (99.7\%) were enrolled after applying inclusion and exclusion criteria. The most common reason for lack of entry was failure to meet the age inclusion criteria $(n=127)$. Of the 40473 eligible patients enrolled in the study, $34760(85.9 \%)$ and $5713(14.1 \%)$ had negative and positive dipstick tests, respectively. Of the 5713 patients with a positive dipstick test, 5393 (94.4\%) had a valid UACR value and were included in the subsequent analyses of albuminuria, whereas 320 (5.6\%) had an invalid UACR value and were excluded from all analyses.

In the overall analysis population $(N=40153), 13.4 \%$ (5393/ 40153 ) of the patients had a positive dipstick result, whereas $86.6 \%$ (34 760/40 153) had a negative dipstick result (Table 1). Of the 5393 patients with a positive dipstick test and a valid UACR value, 2736 (50.7\%) had a normal UACR $<30 \mu \mathrm{g} \mathrm{mg}^{-1}$ and 2657 (49.3\%) patients had albuminuria as defined by a positive dipstick test and a clinically elevated UACR value $\geqslant 30 \mu \mathrm{g} \mathrm{mg}^{-1}$. The albuminuria cohort comprised of 2158/2657 (81.2\%) and 499/2657 (18.8\%) patients with microalbuminuria and macroalbuminuria, respectively. Therefore, in the overall analysis population, after excluding 320 patients with an invalid UACR value, the prevalence of albuminuria, as defined by a positive dipstick test and a clinically elevated UACR value, was $6.6 \%$ (2657/40 153). The prevalences of microalbuminuria (that is, positive dipstick test and a valid UACR $\geqslant 30$ to $<300 \mu \mathrm{g} \mathrm{mg}^{-1}$ ) and macroalbuminuria (that is, positive dipstick test and a valid UACR $\geqslant 300 \mu \mathrm{g} \mathrm{mg}^{-1}$ ) were $5.4 \%(2185 / 40153)$ and $1.2 \%$ (499/40 153), respectively.

The demographic and baseline clinical characteristics of the overall analysis population, including patients with negative and positive dipstick tests, are shown in Table 1 . The overall analysis population comprised of 20462 (51.0\%) women and 19686 (49.0\%) men with a mean \pm s.d. age of $58.5 \pm 10.2$ years. At baseline, the mean \pm s.d. duration of hypertension was $6.1 \pm 5.0$ years, mean \pm s.d. systolic BP (SBP) was $130.2 \pm 11.0 \mathrm{~mm} \mathrm{Hg}$ and mean \pm s.d. diastolic BP (DBP) was $81.8 \pm 7.7 \mathrm{mmHg}$. Most patients were taking one or two antihypertensive medications, primarily angiotensin II receptor blockers $(66.5 \%)$, calcium channel blockers $(45.5 \%)$ and/or thiazide diuretics $(16.1 \%)$ at the time of study enrollment. The majority $(83.5 \%)$ of patients had BP values $\geqslant 130 / 80 \mathrm{~mm} \mathrm{Hg}$ at baseline. Of the patients with available data regarding smoking status, $19.9 \%$ were current smokers and 59.3\% had never smoked. The mean BMI was $24.6 \pm 2.9 \mathrm{~kg} \mathrm{~m}^{-2}$ and the majority of patients were either overweight or obese (that is, $\geqslant 23.0 \mathrm{~kg} \mathrm{~m}^{-2} ; 30.1 \%$ and $40.8 \%$, respectively). The proportion of patients with a history of diabetes, stroke/transient ischemic attack, kidney disease, myocardial infarction and heart failure were $17.6 \%, 5.4 \%, 3.4 \%, 2.5$ and $3.4 \%$, respectively.

The baseline demographic and clinical characteristics were compared across participant subgroups defined by positive $(n=5393)$ and negative $(n=34760)$ dipstick tests (Table 1$)$. Patients with a positive dipstick test were slightly older than those with a negative dipstick test (59.4 vs 58.4 years; $P<0.001$ ). The average duration of hypertension was longer in patients with a positive dipstick test (6.9 vs 6.0 years; $P<0.001)$. The mean BMI value ( 25.1 vs $24.5 \mathrm{~kg} \mathrm{~m}^{-2} ; P<0.001$ ) was slightly higher in patients with a positive dipstick test. Other relevant factors included a higher prevalence of obesity $(47.5 \%$ vs $39.7 \%$; $P<0.001)$ and fewer patients with SBP $<130 \mathrm{~mm} \mathrm{Hg}$ and DBP $<80 \mathrm{mmHg}(15.5 \%$ vs $16.6 \% ; P=0.036)$ among patients with a positive dipstick test. In addition, significantly more patients in the positive dipstick group had a history of diabetes (29.2\% vs $15.9 \%$;
$P<0.001)$, stroke/transient ischemic attack $(6.5 \%$ vs $5.2 \% ; P<0.001)$ and kidney-related disease $(5.2 \%$ vs $3.1 \% ; P<0.001)$ than the dipstick-negative group. The majority of study patients were well adherent to medication regimen, with $80.4 \%$ of patients having a non-adherence score of zero.

Baseline demographic and clinical characteristics were compared across participant subgroups defined by normoalbuminuria ( $n=37496$ (that is, patients with a negative dipstick test or a positive dipstick test and a valid UACR $\left.<30 \mu \mathrm{g} \mathrm{mg}^{-1}\right)$ ), microalbuminuria ( $n=2158$ (patients with a positive dipstick test and a valid UACR $\geqslant 30$ to $\left.<300 \mu \mathrm{g} \mathrm{mg}^{-1}\right)$ ) and macroalbuminuria $(n=499$ (patients with a positive dipstick test and a valid UACR $\left.\geqslant 300 \mu \mathrm{g} \mathrm{mg}^{-1}\right)$ ) in the overall analysis population $(N=40153$; patients with either a negative dipstick test or a positive dipstick test and a valid UACR value; Table 2). Compared with normal patients, patients with albuminuria (including both microalbuminuria and macroalbuminuria) were older (60.1 vs 58.4 years), had a longer duration of hypertension ( 7.6 vs 6.0 years), and a larger proportion were male $(51.7 \%$ vs $48.8 \%)$. Other demographic characteristics with significant differences between normal patients and patients with albuminuria included height $(P=0.001)$, weight $(P<0.001)$, education $(P<0.001)$, use of traditional herbs to reduce BP $(P=0.003)$, use of medication to control blood glucose $(P<0.001)$, alcohol consumption frequency $(P=0.021)$, use of soju alcohol $(P<0.001)$, menopausal status $(P<0.001)$ and level of physical activity $(P<0.001)$ and minutes of physical activity per week $(P=0.006$; Table 2$)$. Clinical characteristics found to demonstrate significant differences between normal patients and those with albuminuria included mean BMI $(P<0.001)$, having controlled BP $(P<0.001)$, mean SBP $(P<0.001)$, mean DBP $(P<0.001)$, current use of calcium channel blockers $(P<0.001)$, use of antihypertensive medications $(P=0.001)$, adherence to antihypertensive medication scale $(P<0.001)$, number of patients with diabetes, stroke or transient ischemic attack, or kidneyrelated disease (all $P<0.001$ ), number of comorbidities except hypertension $(P<0.001)$, number of medications except those for hypertension $(P<0.001)$, and lipids and lipoprotein levels (that is, total cholesterol, high-density lipoprotein cholesterol, LDL-C and triglycerides (all $P<0.001$ ); Table 2).

The prevalences of albuminuria, microalbuminuria and macroalbuminuria also were examined within participant subgroups defined by baseline demographics and clinical characteristics (Table 3). The prevalence of albuminuria increased with age such that $10.2 \%$ of patients $>75$ years had albuminuria compared with only $5.2 \%$ of patients $35-44$ years $(P<0.001$ for all albuminuria classifications). The prevalences of albuminuria and microalbuminuria were greater in men than women $(P \leqslant 0.012$ for albuminuria and microalbuminuria); however, similar prevalences of macroalbuminuria were seen in both men and women $(P=0.147)$. A similar finding was observed for the BMI stratifications, such that higher prevalences of albuminuria and microalbuminuria were seen in overweight and obese patients vs underweight patients; however, the prevalence of macroalbuminuria was relatively consistent across these BMI categories (Table 3). Other factors associated with increased prevalence of albuminuria (including both microalbuminuria and macroalbuminuria) included SBP $\geqslant 130 \mathrm{~mm} \mathrm{Hg}$ and/or DBP $\geqslant 80 \mathrm{~mm} \mathrm{Hg}$, number of antihypertensive medications, poor adherence to antihypertensive medications, prior history of diabetes, stroke/transient ischemic attack or kidney-related disease, and number of comorbidities (Table 3). In contrast, smoking status did not appear to influence the prevalence of albuminuria, nor did a family history of myocardial infarction/sudden death (data not shown). 


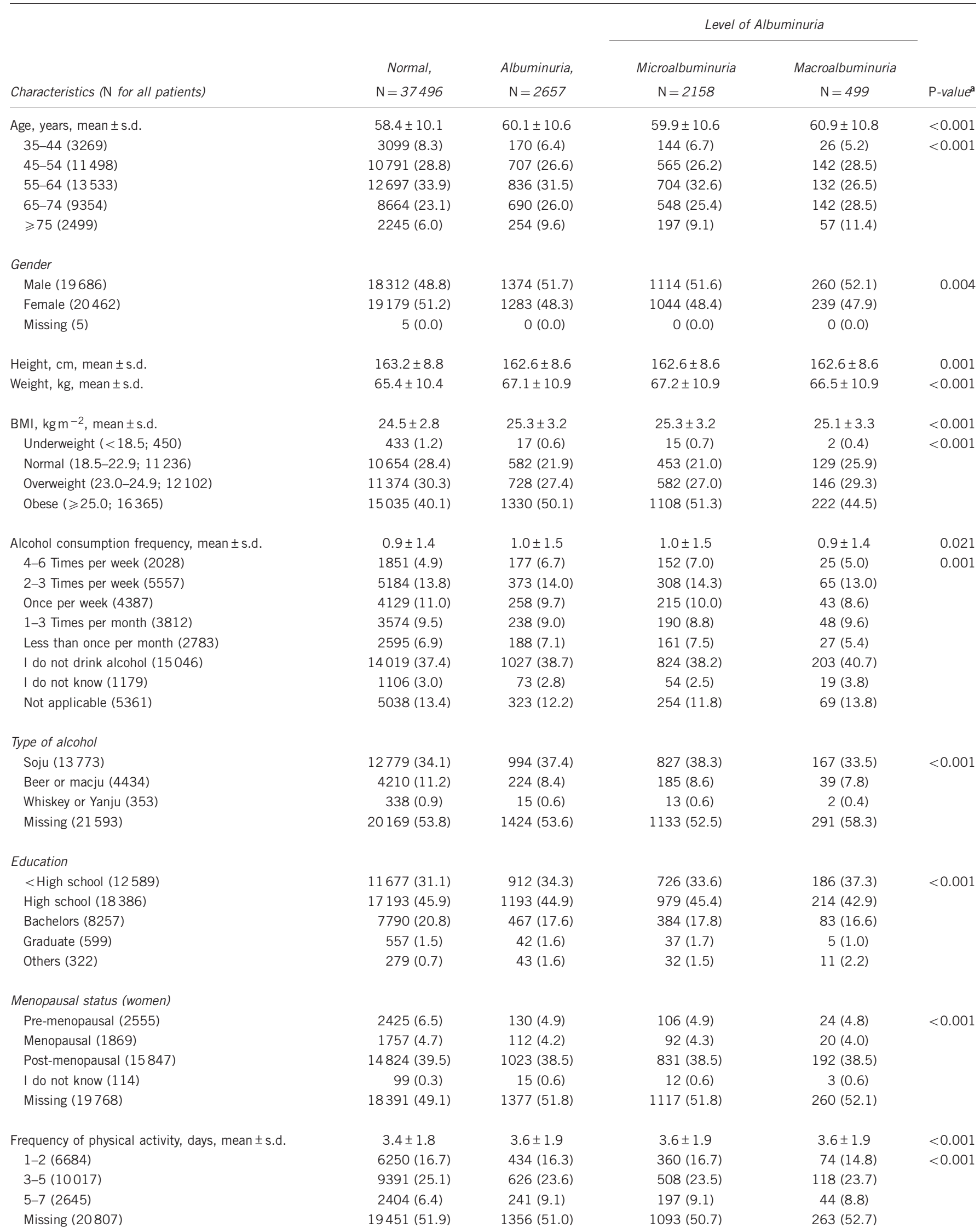




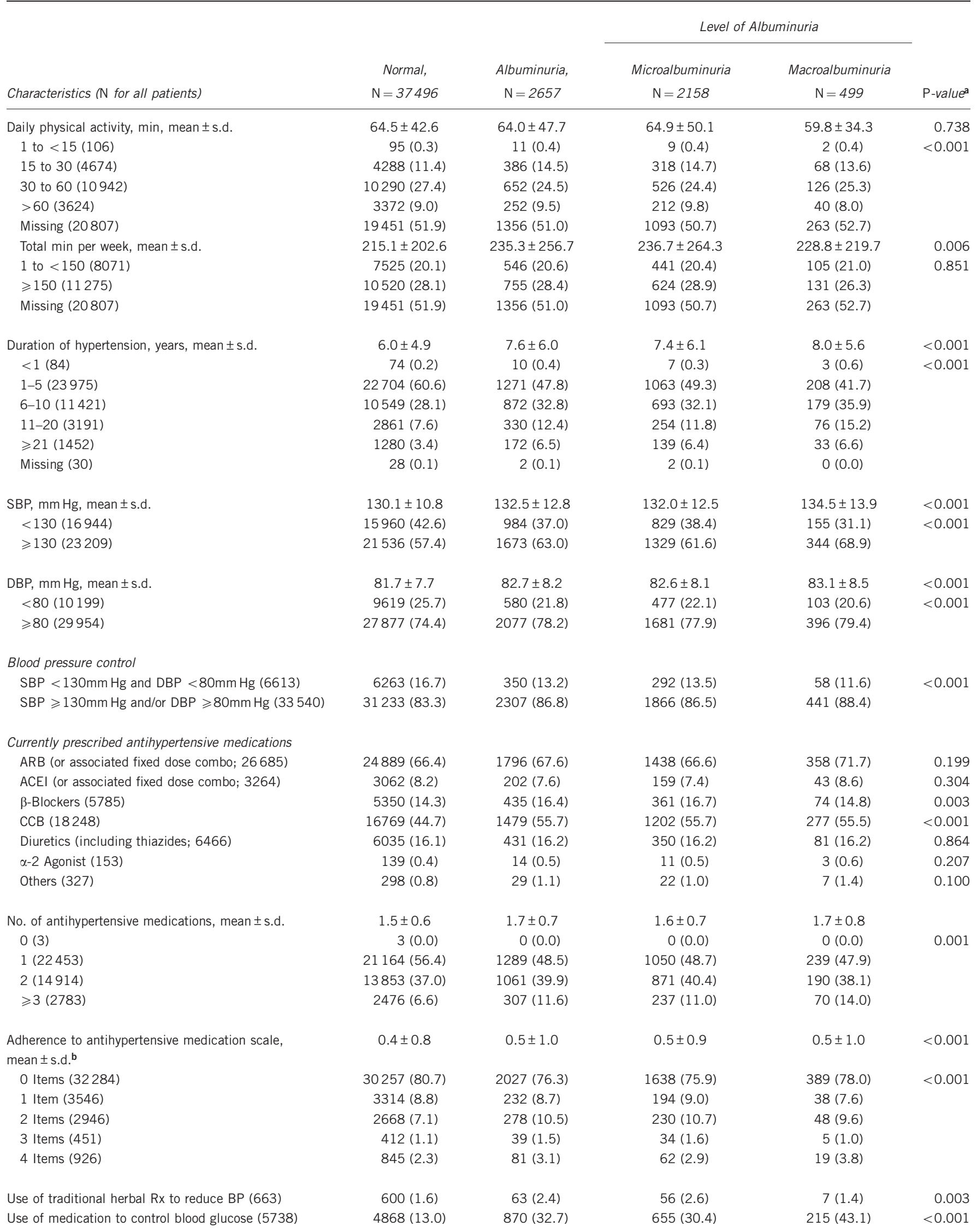




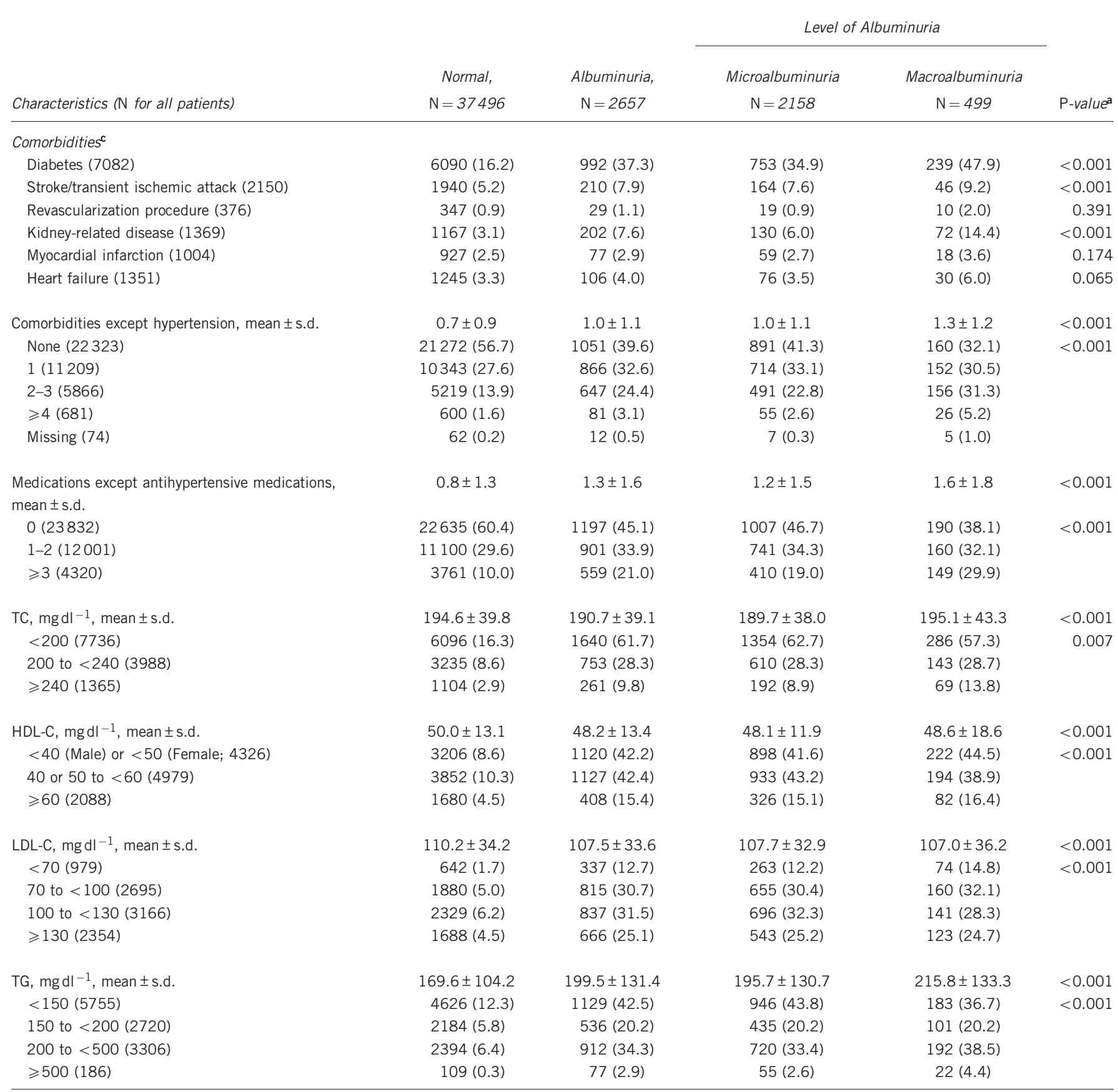

Abbreviations: ACEI, angiotensin-converting enzyme inhibitor; ARB, angiotensin II receptor blocker; BMI, body mass index; BP, blood pressure; CCB, calcium channel blocker; DBP, diastolic blood pressure; HDL-C, high-density lipoprotein cholesterol; LDL-C, low-density lipoprotein cholesterol; SBP, systolic blood pressure; TC, total cholesterol; TG, triglycerides.

Data are shown as $n(\%)$ of patients relative to all patients in the albuminuria category unless otherwise stated.

Data are shown as $n(\%)$ of patients relative to all patients in the albuminuria category unless otherwise stated.
Variables that were not significantly different in the distribution between patients with normal and albuminuria UACR levels (that is, marital status, age at initial diagnosis of hypertension, smoking Variables that were not significantly different in the distribution between patients with normal and albuminuria
status, family history of sudden death, use of fixed dose combination medication) are not shown in the table.

a $P$-value represents the differences in distribution of variables/values between patients with normal and albuminuria urine albumin/creatinine ratio levels and is estimated after excluding patients with the missing values.

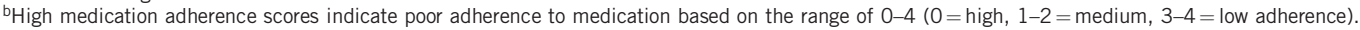

${ }^{c}$ Comorbidities were identified by either physician or patient reports.

Univariate and multivariate logistic regression analyses were performed to determine the influence of various factors on urinary albumin excretion (Table 4). For the purpose of this analysis, data from the microalbuminuria and macroalbuminuria groups were combined together $(n=2657)$ and compared with the normoalbuminuria group ( $n=34760$ (dipstick negative)). The odds of having an elevated UACR value $\geqslant 30 \mu \mathrm{g} \mathrm{mg}^{-1}$ were estimated before (univariate model) and after (multivariate model) adjusting for various factors suspected to be associated with increased urinary albumin excretion. 
Table 3 Prevalence $(N(\%))$ of albuminuria presented by baseline characteristics

\begin{tabular}{|c|c|c|c|}
\hline Total population $(\mathrm{N}=40153)$ & $\begin{array}{l}\text { Albuminuria } \\
(\mathrm{N}=2657)\end{array}$ & $\begin{array}{l}\text { Microalbuminuria } \\
\qquad(\mathrm{N}=2158)\end{array}$ & $\begin{array}{l}\text { Macroalbuminuria } \\
\qquad(\mathrm{N}=499)\end{array}$ \\
\hline \multicolumn{4}{|c|}{ Baseline characteristics ( $\mathrm{N}$ for all patients in category) } \\
\hline \multicolumn{4}{|l|}{ Age, years } \\
\hline $35-44$ (3269) & $170(5.2)^{* *}$ & $144(4.4)^{* *}$ & $26(0.8)^{* *}$ \\
\hline 45-54 (11 498) & $707(6.1)$ & $565(4.9)$ & $142(1.2)$ \\
\hline $55-64(13533)$ & $836(6.2)$ & $704(5.2)$ & $132(1.0)$ \\
\hline $65-74(9354)$ & $690(7.4)$ & $548(5.9)$ & $142(1.5)$ \\
\hline$\geqslant 75$ (2499) & $254(10.2)$ & $197(7.9)$ & $57(2.3)$ \\
\hline \multicolumn{4}{|l|}{ Gender } \\
\hline Male (19686) & $1374(7.0)^{*}$ & $1114(5.7)^{*}$ & $260(1.3)$ \\
\hline Female (20 462) & $1283(6.3)$ & $1044(5.1)$ & $239(1.2)$ \\
\hline \multicolumn{4}{|l|}{$B M I, \mathrm{kgm}^{-2}$} \\
\hline Underweight $(<18.5 ; 450)$ & $17(3.8)^{* *}$ & $15(3.3)^{* *}$ & $2(0.4)$ \\
\hline Normal (18.5-22.9; 11236$)$ & $582(5.2)$ & $453(4.0)$ & $129(1.1)$ \\
\hline Overweight (23.0-24.9; 12 102) & $728(6.0)$ & $582(4.8)$ & $146(1.2)$ \\
\hline Obese $(\geqslant 25.0 ; 16365)$ & $1330(8.1)$ & $1108(6.8)$ & $222(1.4)$ \\
\hline \multicolumn{4}{|l|}{ Alcohol consumption frequency } \\
\hline 4-6 times per week (2028) & $177(8.7)^{*}$ & $152(7.5)^{* *}$ & $25(1.2)$ \\
\hline 2-3 times per week (5557) & $373(6.7)$ & $308(5.5)$ & $65(1.2)$ \\
\hline Once per week (4387) & $258(5.9)$ & $215(4.9)$ & $43(1.0)$ \\
\hline 1-3 times per month (3812) & $238(6.2)$ & $190(5.0)$ & $48(1.3)$ \\
\hline Less than once per month (2783) & $188(6.8)$ & $161(5.8)$ & $27(1.0)$ \\
\hline I do not drink alcohol (15046) & $1027(6.8)$ & $824(5.5)$ & $203(1.3)$ \\
\hline I do not know (1179) & $73(6.2)$ & $54(4.6)$ & $19(1.6)$ \\
\hline Not applicable (5361) & $323(6.0)$ & $254(4.7)$ & $69(1.3)$ \\
\hline \multicolumn{4}{|l|}{ Education } \\
\hline$<$ High school (12 589) & $912(7.2)^{* *}$ & $726(5.8)^{* *}$ & $186(1.5)^{* *}$ \\
\hline High school (18386) & $1193(6.5)$ & $979(5.3)$ & $214(1.2)$ \\
\hline Bachelors (8257) & $467(5.7)$ & $384(4.7)$ & $83(1.0)$ \\
\hline Graduate (599) & $42(7.0)$ & $37(6.2)$ & $5(0.8)$ \\
\hline Other (322) & $43(13.4)$ & $32(9.9)$ & $11(3.4)$ \\
\hline \multicolumn{4}{|l|}{ Menopausal status (women) } \\
\hline Pre-menopausal (2555) & $130(5.1)^{*}$ & $106(4.1)^{*}$ & $24(0.9)$ \\
\hline Menopausal (1869) & $112(6.0)$ & $92(4.9)$ & $20(1.1)$ \\
\hline Post-menopausal (15847) & $1023(6.5)$ & $831(5.2)$ & $192(1.2)$ \\
\hline I do not know (114) & $15(13.2)$ & $12(10.5)$ & $3(2.6)$ \\
\hline \multicolumn{4}{|l|}{ Frequency of physical activity, days } \\
\hline $1-2(6684)$ & $434(6.5)^{* *}$ & $360(5.4)^{* *}$ & $74(1.1)$ \\
\hline $3-5(10017)$ & $626(6.2)$ & $508(5.1)$ & $118(1.2)$ \\
\hline $5-7(2645)$ & $241(9.1)$ & $197(7.4)$ & $44(1.7)$ \\
\hline \multicolumn{4}{|l|}{ Daily physical activity, min } \\
\hline 1 to $<15(106)$ & $11(10.4)^{* *}$ & $9(8.5)^{* *}$ & $2(1.9)$ \\
\hline 15 to 30 (4674) & $386(8.3)$ & $318(6.8)$ & $68(1.5)$ \\
\hline 30 to $60(10942)$ & $652(6.0)$ & $526(4.8)$ & $126(1.2)$ \\
\hline$>60(3624)$ & $252(7.0)$ & $212(5.8)$ & $40(1.1)$ \\
\hline \multicolumn{4}{|l|}{ Duration of hypertension, years } \\
\hline$<1(84)$ & $10(11.9)^{* *}$ & $7(8.3)^{* *}$ & $3(3.6)^{* *}$ \\
\hline $1-5(23975)$ & $1271(5.3)$ & $1063(4.4)$ & $208(0.9)$ \\
\hline $6-10(11421)$ & $872(7.6)$ & $693(6.1)$ & $179(1.6)$ \\
\hline $11-20(3191)$ & $330(10.3)$ & $254(8.0)$ & $76(2.4)$ \\
\hline$\geqslant 21(1452)$ & $172(11.8)$ & $139(9.6)$ & $33(2.3)$ \\
\hline
\end{tabular}


Table 3 (Continued)

\begin{tabular}{|c|c|c|c|}
\hline Total population $(\mathrm{N}=40153)$ & $\begin{array}{l}\text { Albuminuria } \\
(\mathrm{N}=2657)\end{array}$ & $\begin{array}{l}\text { Microalbuminuria } \\
\qquad(\mathrm{N}=2158)\end{array}$ & $\begin{array}{c}\text { Macroalbuminuria } \\
\qquad(\mathrm{N}=499)\end{array}$ \\
\hline \multicolumn{4}{|l|}{$\mathrm{SBP}, \mathrm{mm} \mathrm{Hg}$} \\
\hline$<130(16944)$ & $984(5.8)^{* *}$ & $829(4.9)^{* *}$ & $155(0.9)^{* *}$ \\
\hline$\geqslant 130(23209)$ & $1673(7.2)$ & $1329(5.7)$ & $344(1.5)$ \\
\hline \multicolumn{4}{|l|}{$D B P, m m ~ H g$} \\
\hline$<80$ (10 199) & $580(5.7)^{* *}$ & $477(4.7)^{* *}$ & $103(1.0)^{*}$ \\
\hline$\geqslant 80(29954)$ & $2077(6.9)$ & $1681(5.6)$ & $396(1.3)$ \\
\hline \multicolumn{4}{|l|}{ Blood pressure control } \\
\hline $\mathrm{SBP}<130 \mathrm{~mm} \mathrm{Hg}$ and DBP $<80 \mathrm{~mm} \mathrm{Hg}$ (6613) & $350(5.3)^{* *}$ & $292(4.4)^{* *}$ & $58(0.9)^{*}$ \\
\hline $\begin{array}{l}\mathrm{SBP} \geqslant 130 \mathrm{~mm} \mathrm{Hg} \text { and/or } \mathrm{DBP} \geqslant 80 \mathrm{~mm} \mathrm{Hg} \\
(33540)\end{array}$ & $2307(6.9)$ & $1866(5.6)$ & $441(1.3)$ \\
\hline \multicolumn{4}{|l|}{ Currently prescribed antihypertensive medications } \\
\hline ARB (or associated fixed dose combo; 26685 ) & $1796(6.7)$ & $1438(5.4)$ & $358(1.3)^{*}$ \\
\hline ACEI (or associated fixed dose combo; 3264) & $202(6.2)$ & 159 (4.9) & $43(1.3)$ \\
\hline$\beta$-Blockers (5785) & $435(7.5)^{*}$ & $361(6.2)^{*}$ & $74(1.3)$ \\
\hline CCB (18248) & $1479(8.1)^{* *}$ & $1202(6.6)^{* *}$ & $277(1.5)^{* *}$ \\
\hline Diuretics (including thiazides; 6466) & $431(6.7)$ & $350(5.4)$ & $81(1.3)$ \\
\hline$\alpha-2$ Agonist (153) & $14(9.2)$ & $11(7.2)$ & $3(2.0)$ \\
\hline Others (327) & $29(8.9)$ & $22(6.7)$ & $7(2.1)$ \\
\hline \multicolumn{4}{|l|}{ No. of antihypertensive medications } \\
\hline $0(3)$ & $0(0.0)^{* *}$ & $0(0.0)^{* *}$ & $0(0.0)^{* *}$ \\
\hline $1(22453)$ & $1289(5.7)$ & $1050(4.7)$ & $239(1.1)$ \\
\hline $2(14914)$ & $1061(7.1)$ & $871(5.8)$ & $190(1.3)$ \\
\hline$\geqslant 3(2783)$ & $307(11.0)$ & $237(8.5)$ & $70(2.5)$ \\
\hline \multicolumn{4}{|l|}{ Adherence to antihypertensive medications ${ }^{\mathrm{a}}$} \\
\hline 0 Items (32 284) & $2027(6.3)^{* *}$ & $1638(5.1)^{*}$ & $389(1.2)^{*}$ \\
\hline 1 Item (3546) & $232(6.5)$ & $194(5.5)$ & $38(1.1)$ \\
\hline 2 Items (2946) & $278(9.4)$ & $230(7.8)$ & $48(1.6)$ \\
\hline 3 Items (451) & $39(8.6)$ & $34(7.5)$ & $5(1.1)$ \\
\hline 4 Items (926) & $81(8.7)$ & $62(6.7)$ & $19(2.1)$ \\
\hline Use of medication to control blood glucose (5738) & $870(15.2)^{* *}$ & $655(11.4)^{* *}$ & $215(3.7)^{* *}$ \\
\hline \multicolumn{4}{|l|}{ Comorbidities $^{b}$} \\
\hline Diabetes (7082) & $992(14.0)^{* *}$ & $753(10.6)^{* *}$ & $239(3.4)^{* *}$ \\
\hline Stroke/transient ischemic attack (2150) & $210(9.8)^{* *}$ & $164(7.6)^{* *}$ & $46(2.1)^{*}$ \\
\hline Revascularization procedure (376) & $29(7.7)$ & $19(5.1)$ & $10(2.7)^{*}$ \\
\hline Kidney-related disease (1369) & $202(14.8)^{* *}$ & $130(9.5)^{* *}$ & $72(5.3)^{* *}$ \\
\hline Myocardial infarction (1004) & $77(7.7)$ & $59(5.9)$ & $18(1.8)$ \\
\hline Heart failure (1351) & $106(7.8)$ & $76(5.6)$ & $30(2.2)^{*}$ \\
\hline \multicolumn{4}{|l|}{ Number of comorbidities except hypertension } \\
\hline $0(22323)$ & $1051(4.7)^{* *}$ & $891(4.0)^{* *}$ & $160(0.7)^{* *}$ \\
\hline 1 (11209) & $866(7.7)$ & $714(6.4)$ & $152(1.4)$ \\
\hline $2-3(5866)$ & $647(11.0)$ & $491(8.4)$ & $156(2.7)$ \\
\hline$\geqslant 4(681)$ & $81(11.9)$ & $55(8.1)$ & $26(3.8)$ \\
\hline \multicolumn{4}{|l|}{ TC, $m g d l^{-1}$} \\
\hline$<200$ (7736) & $1640(21.2)^{*}$ & $1354(17.5)^{*}$ & $286(3.7)$ \\
\hline 200 to $<240$ (3988) & 753 (18.9) & $610(15.3)$ & $143(3.6)$ \\
\hline$\geqslant 240(1365)$ & $261(19.1)$ & $192(14.1)$ & $69(5.1)$ \\
\hline
\end{tabular}




\begin{tabular}{|c|c|c|c|}
\hline Total population $(\mathrm{N}=40153)$ & $\begin{array}{l}\text { Albuminuria } \\
(\mathrm{N}=2657)\end{array}$ & $\begin{array}{l}\text { Microalbuminuria } \\
\qquad(\mathrm{N}=2158)\end{array}$ & $\begin{array}{c}\text { Macroalbuminuria } \\
\qquad(\mathrm{N}=499)\end{array}$ \\
\hline \multicolumn{4}{|l|}{$H D L-C, m g d l^{-1}$} \\
\hline$<40$ (male) or $<50$ (female; 4326) & $1120(25.9)^{* *}$ & $898(20.8)^{* *}$ & $222(5.1)^{*}$ \\
\hline 40 or 50 to $<60$ (4979) & $1127(22.6)$ & $933(18.7)$ & $194(3.9)$ \\
\hline$\geqslant 60(2088)$ & 408 (19.5) & $326(15.6)$ & $82(3.9)$ \\
\hline \multicolumn{4}{|l|}{$L D L-C, \mathrm{mgdl}^{-1}$} \\
\hline$<70$ (979) & $337(34.4)^{* *}$ & 263 (26.9) & $74(7.6)^{*}$ \\
\hline 70 to $<100$ (2695) & $815(30.2)$ & $655(24.3)$ & $160(5.9)$ \\
\hline 100 to $<130(3166)$ & $837(26.4)$ & $696(22.0)$ & $141(4.5)$ \\
\hline$\geqslant 130(2354)$ & $666(28.3)$ & $543(23.1)$ & $123(5.2)$ \\
\hline \multicolumn{4}{|l|}{$T G, m g d l^{-1}$} \\
\hline$<150(5755)$ & $1129(19.6)^{* *}$ & $946(16.4)^{* *}$ & $183(3.2)^{* *}$ \\
\hline 150 to $<200(2720)$ & $536(19.7)$ & 435 (16.0) & $101(3.7)$ \\
\hline 200 to $<500$ (3306) & $912(27.6)$ & $720(21.8)$ & $192(5.8)$ \\
\hline$\geqslant 500(186)$ & $77(41.4)$ & $55(29.6)$ & $22(11.8)$ \\
\hline
\end{tabular}

In the univariate analysis, elevated UACR was associated with age, gender, smoking status, BMI classifications, duration of hypertension, SBP $\geqslant 130 \mathrm{~mm} \mathrm{Hg}$ and/or DBP $\geqslant 80 \mathrm{~mm} \mathrm{Hg}$, baseline LDL-C value classifications, currently prescribed antihypertensive medication, number of antihypertensive medications, adherence to antihypertensive medication scale and comorbidities of diabetes, stroke/ ischemic attack and kidney-related disease, and number of medications excluding antihypertensive medications (Table 4). After adjusting for the confounding effects of factors associated with elevated UACR in the univariate analysis (Table 4), the remaining independent determinants of an elevated UACR value in the multivariate analysis were low adherence to antihypertensive medication (OR 1.23 (95\% CI: 1.01, 1.50; $P=0.042$ )), uncontrolled BP (OR 1.38 (95\% CI: 1.23, 1.56; $P<0.001$ ) for SBP $\geqslant 130 \mathrm{~mm} \mathrm{Hg}$ and/or DBP $\geqslant 80 \mathrm{~mm} \mathrm{Hg}$ ), obesity (OR $1.47 \quad(95 \%$ CI: $1.32,1.63 ; \quad P<0.001)$ for $\mathrm{BMI}$ $\left.\geqslant 25.0 \mathrm{~kg} \mathrm{~m}^{-2}\right)$, number of antihypertensive medications (ORs 1.13 (95\% CI: 1.03, 1.23; $P=0.007)$ and $1.51(1.31,1.73$; $P<0.001)$ for 2 and $\geqslant 3$ antihypertensive drugs, respectively), age (ORs 0.83 (95\% CI: $0.70,0.99 ; P=0.043)$ and $1.58(1.35,1.85$; $P<0.001)$ for 35 - to 44 -year and $>75$-year categories, respectively), as well as a prior history of diabetes (OR 2.51 (95\% CI: 2.26, 2.78; $P<0.001)$ ) or kidney-related disease (OR $1.71(1.45,2.03 ; P<0.001)$ ).

\section{DISCUSSION}

This large, cross-sectional study explored the prevalence of albuminuria and identify the independent factors associated with microalbuminuria among Korean patients with essential/primary hypertension receiving treatment in the primary care setting. This study is the largest known epidemiological study $(N=40473)$ conducted in hypertensive patients undergoing management by primary care physicians in any one country. Albuminuria was detected through the combined use of urine dipstick tests and UACR laboratory values. At the screening visit, physicians collected clinical and demographic information on adult (that is, $\geqslant 35$ years) patients who were diagnosed with primary/essential hypertension or were taking antihypertensive medication to better characterize the following: (1) prevalence of albuminuria in the urine as assessed by a positive dipstick test alone, (2) prevalence of microalbuminuria in the urine as assessed by a positive dipstick test and a valid UACR test $\geqslant 30$ to $<300 \mu \mathrm{g} \mathrm{mg}^{-1}$; (3) the clinical and demographic characteristics associated with albuminuria and microalbuminuria in Koreans.

Results of this study show that a significant proportion of Korean hypertensive patients have albuminuria. The frequency of albuminuria in the overall study population as determined by a positive dipstick test was $13.4 \%$ (5393/40 153), irrespective of UACR testing. Of the study patients with a positive dipstick test, approximately half were subsequently found to have normal urinary albumin excretion levels (UACR $<30 \mu \mathrm{g} \mathrm{mg}^{-1} ; 50.7 \% ; 2736 / 5393$ ) and the other half had albuminuria (UACR $\geqslant 30 \mu \mathrm{g} \mathrm{mg}^{-1} ; 49.3 \%$; 2657/5393) demonstrating the high false positive rate associated with dipstick testing. Hence, the actual prevalence of albuminuria as determined by a positive dipstick test in conjunction with an increased UACR $\geqslant 30 \mu \mathrm{g} \mathrm{mg}^{-1}$ was substantially lower at $6.6 \%$ (2657/40 153). More specifically, the prevalences of microalbuminuria and macroalbuminuria were 5.4\% (2185/40 153) and 1.2\% (499/40 153), respectively. Of the patients with albuminuria determined by UACR testing, $81.2 \%$ $(2158 / 2657)$ and $18.8 \%(499 / 2657)$ were classified as having microalbuminuria and macroalbuminuria, respectively.

Patients with albuminuria tended to be older, had a longer duration of hypertension and had a higher prevalence of obesity and SBP $\geqslant 130 \mathrm{~mm} \mathrm{Hg}$ and/or DBP $\geqslant 80 \mathrm{~mm} \mathrm{Hg}$ compared with patients with normoalbuminuria (that is, having a negative dipstick test or a positive dipstick test and a valid UACR value $<30 \mu \mathrm{g} \mathrm{mg}^{-1}$ $(N=37496))$. A previous history of stroke/transient ischemic attack, kidney-related disease and especially diabetes were observed more frequently in patients with vs those without albuminuria. Several factors were found to be independently associated with microalbuminuria in the multivariate model, including age, medication 
Table $4 \mathrm{ORs}^{\mathrm{a}}$ and $95 \% \mathrm{Cls}$ for the presence of elevated urinary albumin excretion: univariate and multivariate analyses

\begin{tabular}{|c|c|c|c|c|c|c|}
\hline \multirow[b]{2}{*}{$\mathrm{N}=40153$} & \multirow[b]{2}{*}{ All patients } & \multirow[b]{2}{*}{ Albuminuria } & \multicolumn{2}{|c|}{ Univariate model } & \multicolumn{2}{|c|}{ Multivariable model (Stepwise regression) } \\
\hline & & & OR $(95 \% \mathrm{Cl})$ & P-value & OR $(95 \% \mathrm{Cl})$ & P-value \\
\hline \multicolumn{7}{|l|}{ Age, years } \\
\hline $35-44$ & 3269 & 170 & $0.84(0.71-1.00)$ & 0.043 & $0.83(0.70-0.99)$ & 0.043 \\
\hline $45-54$ & 11498 & 707 & 1 & & 1 & \\
\hline $55-64$ & 13533 & 836 & $1.01(0.91-1.11)$ & 0.925 & $0.94(0.84-1.04)$ & 0.243 \\
\hline $65-74$ & 9354 & 690 & $1.22(1.09-1.36)$ & $<0.001$ & $1.08(0.97-1.21)$ & 0.175 \\
\hline$\geqslant 75$ & 2499 & 254 & $1.73(1.49-2.01)$ & $<0.001$ & $1.58(1.35-1.85)$ & $<0.001$ \\
\hline \multicolumn{7}{|l|}{ Gender } \\
\hline Male & 19686 & 1374 & 1 & & & \\
\hline Female & 20462 & 1283 & $0.89(0.82-0.97)$ & 0.004 & & \\
\hline \multicolumn{7}{|l|}{ Smoking status } \\
\hline Never & 23800 & 1544 & 1 & & & \\
\hline Former (quit > 1month) & 7194 & 469 & $1.01(0.90-1.12)$ & 0.923 & & \\
\hline Current & 7994 & 570 & $1.11(1.00-1.22)$ & 0.046 & & \\
\hline \multicolumn{7}{|l|}{ Gender and smoking interaction } \\
\hline Female and never & 18442 & 1168 & 1 & & 1 & \\
\hline Female and former (quit $>1$ month) & 791 & 31 & $0.60(0.42-0.87)$ & 0.007 & $0.61(0.42-0.87)$ & 0.007 \\
\hline Female and current & 663 & 46 & $1.10(0.81-1.50)$ & 0.531 & $1.04(0.76-1.42)$ & 0.796 \\
\hline Male and never & 5354 & 376 & $1.12(0.99-1.26)$ & 0.072 & $1.12(0.99-1.27)$ & 0.065 \\
\hline Male and former (quit > 1 month) & 6403 & 438 & $1.09(0.97-1.22)$ & 0.155 & $1.01(0.90-1.13)$ & 0.899 \\
\hline Male and current & 7330 & 524 & $1.14(1.02-1.27)$ & 0.017 & $1.10(0.99-1.23)$ & 0.083 \\
\hline \multicolumn{7}{|l|}{$B M I, \mathrm{kgm}^{-2}$} \\
\hline Underweight $(<18.5)$ & 450 & 17 & $0.72(0.44-1.18)$ & 0.188 & $0.75(0.44-1.27)$ & 0.283 \\
\hline Normal (18.5-22.9) & 11236 & 582 & 1 & & 1 & \\
\hline Overweight (23.0-24.9) & 12102 & 728 & $1.17(1.05-1.31)$ & 0.006 & $1.11(0.99-1.25)$ & 0.071 \\
\hline Obesity $(\geqslant 25.0)$ & 16365 & 1330 & $1.62(1.46-1.79)$ & $<0.001$ & $1.47(1.32-1.63)$ & $<0.001$ \\
\hline \multicolumn{7}{|l|}{ Marital status } \\
\hline Not married & 602 & 29 & 1 & & & \\
\hline Married & 39551 & 2628 & $1.41(0.97-2.04)$ & 0.075 & & \\
\hline \multicolumn{7}{|l|}{ Physical activity } \\
\hline \multicolumn{7}{|l|}{ Total min per week } \\
\hline$<150$ & 8071 & 546 & 1 & & & \\
\hline$\geqslant 150$ & 11275 & 755 & $0.99(0.88-1.11)$ & 0.851 & & \\
\hline \multicolumn{7}{|l|}{ Duration of hypertension, years } \\
\hline$<1$ & 84 & 10 & $2.41(1.24-4.68)$ & 0.009 & & \\
\hline $1-5$ & 23975 & 1271 & 1 & & & \\
\hline $6-10$ & 11421 & 872 & $1.48(1.35-1.61)$ & $<0.001$ & & \\
\hline $11-20$ & 3191 & 330 & $2.06(1.81-2.34)$ & $<0.001$ & & \\
\hline$\geqslant 21$ & 1452 & 172 & $2.40(2.03-2.84)$ & $<0.001$ & & \\
\hline \multicolumn{7}{|l|}{ Blood pressure control } \\
\hline Controlled (SBP $<130$ and DBP $<80 \mathrm{~mm} \mathrm{Hg}$ ) & 6613 & 350 & 1 & & 1 & \\
\hline Uncontrolled (SBP $\geqslant 130$ and/or DBP $\geqslant 80 \mathrm{~mm} \mathrm{Hg}$ ) & 33540 & 2307 & $1.32(1.18-1.48)$ & $<0.001$ & $1.38(1.23-1.56)$ & $<0.001$ \\
\hline \multicolumn{7}{|l|}{ Currently prescribed antihypertensive medications } \\
\hline ARB (or associated fixed dose combo) & 26685 & 1796 & $1.06(0.97-1.15)$ & 0.199 & & \\
\hline ACEI (or associated fixed dose combo) & 3264 & 202 & $0.93(0.80-1.07)$ & 0.304 & & \\
\hline$\beta$-Blockers & 5785 & 435 & $1.18(1.06-1.31)$ & 0.003 & & \\
\hline $\mathrm{CCB}$ & 18248 & 1479 & $1.55(1.43-1.68)$ & $<0.001$ & & \\
\hline Diuretics (including thiazides) & 6466 & 431 & $1.01(0.91-1.12)$ & 0.864 & & \\
\hline$\alpha-2$ Agonist & 153 & 14 & $1.43(0.82-2.47)$ & 0.207 & & \\
\hline Others & 327 & 29 & $1.38(0.94-2.02)$ & 0.100 & & \\
\hline
\end{tabular}




\begin{tabular}{|c|c|c|c|c|c|c|}
\hline \multirow[b]{2}{*}{$N=40153$} & \multirow[b]{2}{*}{ All patients } & \multirow[b]{2}{*}{ Albuminuria } & \multicolumn{2}{|l|}{ Univariate model } & \multicolumn{2}{|c|}{ Multivariable model (Stepwise regression) } \\
\hline & & & OR $(95 \% \mathrm{Cl})$ & P-value & OR $(95 \% \mathrm{Cl})$ & P-value \\
\hline \multicolumn{7}{|l|}{ No. of antihypertensive medications } \\
\hline 0 & 3 & 0 & NA & & & \\
\hline 1 & 22453 & 1289 & 1 & & 1 & \\
\hline 2 & 14914 & 1061 & $1.26(1.16-1.37)$ & $<0.001$ & $1.13(1.03-1.23)$ & 0.007 \\
\hline$\geqslant 3$ & 2783 & 307 & $2.04(1.79-2.32)$ & $<.001$ & $1.51(1.31-1.73)$ & $<0.001$ \\
\hline \multicolumn{7}{|l|}{ Adherence to antihypertensive medication scale ${ }^{\mathrm{b}}$} \\
\hline High (0 items) & 32284 & 2027 & 1 & & 1 & \\
\hline Medium (1-2 items) & 6492 & 510 & $1.27(1.15-1.41)$ & $<0.001$ & $1.05(0.94-1.16)$ & 0.413 \\
\hline Low (3-4 items) & 1377 & 120 & $1.43(1.18-1.73)$ & $<0.001$ & $1.23(1.01-1.50)$ & 0.042 \\
\hline Use of traditional herbal $\mathrm{Rx}$ to reduce $\mathrm{BP}$ & 663 & 63 & $1.49(1.15-1.94)$ & 0.003 & & \\
\hline Use of medication to control blood glucose & 5738 & 870 & $3.26(2.99-3.56)$ & $<0.001$ & & \\
\hline \multicolumn{7}{|l|}{ Comorbidities $^{c}$} \\
\hline Diabetes & 7082 & 992 & $3.07(2.83-3.34)$ & $<0.001$ & $2.51(2.26-2.78)$ & $<0.001$ \\
\hline Stroke/transient ischemic attack & 2150 & 210 & $1.57(1.36-1.82)$ & $<0.001$ & & \\
\hline Revascularization procedure & 376 & 29 & $1.18(0.81-1.73)$ & 0.391 & & \\
\hline Kidney-related disease & 1369 & 202 & $2.56(2.19-2.99)$ & $<0.001$ & $1.71(1.45-2.03)$ & $<0.001$ \\
\hline Myocardial infarction & 1004 & 77 & $1.18(0.93-1.49)$ & 0.175 & & \\
\hline Heart failure & 1351 & 106 & $1.21(0.99-1.48)$ & 0.065 & & \\
\hline \multicolumn{7}{|l|}{ Number of comorbidities except hypertension } \\
\hline None & 22323 & 1051 & 1 & & & \\
\hline 1 & 11209 & 866 & $1.70(1.54-1.86)$ & $<0.001$ & & \\
\hline $2-3$ & 5866 & 647 & $2.51(2.27-2.78)$ & $<0.001$ & & \\
\hline$\geqslant 4$ & 681 & 81 & $2.73(2.15-3.47)$ & $<0.001$ & & \\
\hline \multicolumn{7}{|c|}{ No. of medications except antihypertensive medications } \\
\hline 0 & 23832 & 1197 & 1 & & 1 & \\
\hline $1-2$ & 12001 & 901 & $1.54(1.40-1.68)<0.001$ & & $1.02(0.92-1.13)$ & 0.739 \\
\hline$\geqslant 3$ & 4320 & 559 & $2.81(2.53-3.13)<0.001$ & & $1.34(1.17-1.53)$ & $<0.001$ \\
\hline \multicolumn{7}{|l|}{ LDL-cholesterol, $\mathrm{mgdl}^{-1}$} \\
\hline$<70$ & 979 & 337 & 1 & & & \\
\hline $70-<100$ & 2695 & 815 & $0.83(0.71-0.97)$ & 0.158 & & \\
\hline $100-<130$ & 3166 & 837 & $0.69(0.59-0.80)$ & $<0.001$ & & \\
\hline$\geqslant 130$ & 2354 & 666 & $0.75(0.64-0.88)$ & $<0.001$ & & \\
\hline
\end{tabular}

Abbreviations: ACEI, angiotensin-converting enzyme inhibitor; ARB, angiotensin II receptor blocker; BMI, body mass index; CCB, calcium channel blocker; CI, confidence interval; DBP, diastolic blood pressure; LDL, low-density lipoprotein; NA, not applicable; OR, odds ratio; SBP, systolic blood pressure.

aOdds ratios of albuminuria were calculated using logistic regression.

bHigh medication adherence scores indicate poor adherence to medication based on the range of $0-4(0=$ high, $1-2=$ medium, $3-4=$ low adherence $)$.

cComorbidities were identified by either physician or patient reports.

adherence, obesity, SBP $\geqslant 130 \mathrm{~mm} \mathrm{Hg}$ and/or DBP $\geqslant 80 \mathrm{~mm} \mathrm{Hg}$, number of antihypertensive medications, and a previous history of diabetes or kidney disease. More specifically, patients $<45$ years were $17 \%$ less likely to have microalbuminuria, whereas patients $\geqslant 75$ years were $58 \%$ more likely to have microalbuminuria than those $45-54$ years of age. Patients with low adherence to their antihypertensive medications were $23 \%$ more likely to have elevated UACR value than patients in the high-adherence category. Other factors, such as, BP ( $38 \%$ increased risk), obesity ( $47 \%$ increased risk) and taking two or three, or more antihypertensive medications (13\% and 51\% increased risk, respectively) also were significantly associated with elevated UACR values. By comparison, the presence of comorbidities, such as kidney-related disease $(71 \%$ increased risk) and diabetes $(151 \%$ increased risk) were the overall strongest determinants of elevated UACR values relative to all other factors. It should be noted that the possible role of LDL-C as a determinant of microalbuminuria was difficult to assess in this study because of widespread missing data among the study patients. The univariate analyses did show a possible role of elevated LDL-C levels in decreasing the risk of microalbuminuria; however, this factor did not remain as an independent predictor in the multivariate analyses possibly due to the small numbers of patients with valid LDL-C values.

Previous studies in the Asia Pacific region have estimated the prevalence of microalbuminuria to be the range of $10.0-13.7 \%$ among hypertensive patients, ${ }^{7,8,24} 15.0-20.3 \%$ among diabetic patients ${ }^{26,27,47}$ and $22.2-48.5 \%$ among diabetic hypertensive patients. ${ }^{28-35}$ To date, 
most Korean-based epidemiologic studies have examined the prevalence of microalbuminuria specifically in patients with type 2 diabetes (either with or without regard to their hypertension status) and have reported rates in the range of $12.4-25.3 \%$. One recent study found an incidence rate of $13.2 \%$ in the general population of Chon-Buk province (that is, rural southwestern Korea), irrespective of diabetes status. In that study, an incidence rate of $21.8 \%$ was seen specifically in patients with diabetes. In the current study, the prevalences of microalbuminuria were found to be $10.6 \%$ in diabetics and $5.4 \%$ in the overall hypertensive study population. The reason for the apparently lower prevalence of microalbuminuria seen in this study compared with other Korean-based studies is unknown, but may be due to differences in the techniques used to measure urinary albumin levels, different threshold values used to categorize patients with/without microalbuminuria and different study populations. However, the prevalence rate of microalbuminuria reported herein is likely to be more indicative of the actual rate in Korean hypertensive patients, because this study enrolled a very large number of patients from primary care practices throughout the country. In Korea, most hypertensive patients are diagnosed and treated by primary care physicians rather than specialists.

Single dipstick testing for the detection of microalbuminuria is an established screening tool in a population setting. However, several false positives (50.7\%) resulted from use of the Micral dipstick test as an initial screening tool in this study. Slightly under half $(49.3 \%)$ of the patients with a positive dipstick test were subsequently shown to have an elevated UACR value. The urine dipstick test is a low-cost, semiquantitative measurement that tends to overestimate urine albumin measurements with a sensitivity of 95\% (CI: 90-99\%) and specificity $>80 \%$ (CI: 70-90\%). The false positive rate of the dipstick test used in this study falls within the quoted range for specificity. The false negative rate of the dipstick test (that is, use of UACR values to confirm absence of albuminuria in dipstick negative patients) was not determined; however, there must have been some patients with albuminuria that went undetected by dipstick testing in this study. Overall, the dipstick test did prove useful for screening and identifying a large number of patients with a higher chance of having albuminuria; however, a more quantitative measurement of albuminuria was needed to rule out microalbuminuria in a large proportion of dipstick-positive patients.

Several limitations should be considered when interpreting the results of this study. First, a single-spot urine sample was collected to measure urinary albumin excretion in study patients. By comparison, International guidelines recommend that microalbuminuria be established by three separate tests, of which two measurements should be positive. ${ }^{48}$ Prior studies have shown that urinary albumin levels demonstrate considerable intra-individual variability; therefore, multiple measurements are preferred for the diagnosis of microalbuminuria in the clinical practice setting. ${ }^{49}$ Nevertheless, studies have shown the measurement of UACR from first-morning voided urine samples correlate well with albumin excretion rate as measured by 24 -h urine collection. ${ }^{50}$ Furthermore, UACR has been shown to be a good predictor of cardiovascular morbidity and allcause mortality. ${ }^{48}$ Second, the traditional UACR cut point of $\geqslant 30$ to $<300 \mu \mathrm{g} \mathrm{mg}^{-1}$ was used in this study to identify hypertensive patients with microalbuminuria. This threshold value was initially derived from studies assessing the risk for developing nephropathy in patients with diabetes. ${ }^{9,10}$ Several prospective studies have recently shown that apparently healthy individuals demonstrate an increased risk of cardiovascular disease and death at UACR values below this threshold..$^{9,51-54}$ As a result, the use of the more stringent UACR cut point to define albuminuria in this study may have excluded some hypertensive patients who remain at an increased risk and thus require more intensive management.

Another limitation is the use of office-obtained BP measurements rather than 24-h ambulatory BP measurements in this study. In general, BP values and albuminuria are more closely associated when BP is recorded through the more precise method of ambulatory monitoring. ${ }^{55,56}$ Because BP varies both diurnally and over longer periods of time, the use of one or two office measurements cannot fully describe the BP pattern for any given patient. Although ambulatory BP is the gold standard for monitoring BP status in the real-world setting, such measurements are not feasible in large epidemiologic studies. There is also the potential for selection bias and confounding as this study population consisted of a self-selected group of patients who agreed to enter the study and undergo study procedures. As a result, the results of this study may not be generalizable to all Korean hypertensive patients, such as those treated by specialists. This was a cross-sectional study; thus causal inferences cannot be established and should be considered hypothesisgenerating only. Lastly, the absence of serum creatinine measurements is considered a limitation of this study. The study was conducted in nationwide survey of primary care clinics in Korea, and measurement of serum creatinine concentration is not routine clinical practice in these clinics.

Despite the aforementioned limitations, the present study is the first large epidemiologic survey designed to determine the prevalence of microalbuminuria among individuals with primary/essential hypertension in Korea. The prevalence of microalbuminuria was $5.4 \%$, demonstrating that hypertensive kidney damage is present in a significant number of Korean hypertensive patients in the clinical practice setting. More routine UACR testing of Korean hypertensive patients may enable clinicians to detect albuminuria before target organ damage occurs. Clinicians should highly suspect the presence of microalbuminuria in Korean hypertensive patients who are older, obese, have SBP $\geqslant 130 \mathrm{~mm} \mathrm{Hg}$ and/or DBP $\geqslant 80 \mathrm{~mm} \mathrm{Hg}$ (that is, either through inadequate treatment or poor medication adherence) or difficult to control (that is, taking $>3$ antihypertensive medications) BP, and particularly in patients with established kidney disease or diabetes. Hypertensive patients should be encouraged to implement healthy lifestyle changes to reduce body weight, control BP and improve blood sugar levels. Where appropriate, clinicians should aggressively manage cardiovascular risk factors (for example, hypertension, diabetes, dyslipidemia and kidney disease) with pharmacologic therapy to slow progression of nephropathy and avoid endstage renal disease in hypertensive patients with albuminuria.

\section{CONFLICT OF INTEREST}

Authors Yong Soo Kim, David Wu and Amy O Johnson-Levonas are current or former employees of Merck Sharp \& Dohme Corp., a subsidiary of Merck \& Co., Inc., and may own stock or hold stock options in the company. ByungHee Oh reports that grants have been provided to the institution by BMSPfizer, Otsuka and Boryung. Yon Su Kim reports being a member of a board. The remaining authors declare no conflict of interest.

\section{ACKNOWLEDGEMENTS}

Funding for this study was provided by Merck Sharp \& Dohme Corp., a subsidiary of Merck \& Co., Inc., Whitehouse Station, NJ, USA. Editorial assistance for this manuscript was provided by Myoung Jin Lee of MSD Korea Ltd., and Kathleen Newcomb, Kristen Lewis and Janice Grant of Merck Sharp \& Dohme Corp. 
1 Cerasola G, Cottone S, Mule G. The progressive pathway of microalbuminuria: from early marker of renal damage to strong cardiovascular risk predictor. J Hypertens 2010; 28: 2357-2369.

2 Parving HH, Oxenboll B, Svendsen PA, Christiansen JS, Andersen AR. Early detection of patients at risk of developing diabetic nephropathy. A longitudinal study of urinary albumin excretion. Acta Endocrinol (Copenh) 1982; 100: 550-555.

3 Viberti GC, Hill RD, Jarrett RJ, Argyropoulos A, Mahmud U, Keen H. Microalbuminuria as a predictor of clinical nephropathy in insulin-dependent diabetes mellitus. Lancet 1982; 1: 1430-1432.

4 Haneda M, Kikkawa R, Togawa M, Koya D, Kajiwara N, Uzu T, Shigeta Y. High blood pressure is a risk factor for the development of microalbuminuria in Japanese subjects with non-insulin-dependent diabetes mellitus. J Diabetes Complications 1992; 6 181-185.

5 Wachtell $\mathrm{K}$, Ibsen $\mathrm{H}$, Olsen $\mathrm{MH}$, Borch-Johnsen $\mathrm{K}$, Lindholm LH, Mogensen CE, Dahlof B, Devereux RB, Beevers G, de Faire U, Fyhrquist F, Julius S, Kjeldsen SE, Kristianson K, Lederballe-Pedersen O, Nieminen MS, Okin PM, Omvik P, Oparil S, Wedel H, Snapinn SM, Aurup P. Albuminuria and cardiovascular risk in hypertensive patients with left ventricular hypertrophy: the LIFE study. Ann Intern Med 2003; 139: 901-906.

6 Forman JP, Brenner BM. 'Hypertension' and 'microalbuminuria': the bell tolls for thee Kidney Int 2006; 69: 22-28.

7 Choi HS, Sung KC, Lee KB. The prevalence and risk factors of microalbuminuria in normoglycemic, normotensive adults. Clin Nephrol 2006; 65: 256-261.

8 Konta T, Hao Z, Abiko H, Ishikawa M, Takahashi T, Ikeda A, Ichikawa K, Takasaki S, Kubota I. Prevalence and risk factor analysis of microalbuminuria in Japanese general population: the Takahata study. Kidney Int 2006; 70: 751-756.

9 National Kidney Foundation. K/DOQI clinical practice guidelines for chronic kidney disease: evaluation, classification, and stratification. Am J Kidney Dis 2002, 39: S1-266.

10 Mancia G, De Backer G, Dominiczak A, Cifkova R, Fagard R, Germano G, Grassi G, Heagerty AM, Kjeldsen SE, Laurent S, Narkiewicz K, Ruilope L, Rynkiewicz A, Schmieder RE, Boudier HA, Zanchetti A, Vahanian A, Camm J, De Caterina R, Dean V, Dickstein K, Filippatos G, Funck-Brentano C, Hellemans I, Kristensen SD, McGregor K, Sechtem U, Silber S, Tendera M, Widimsky P, Zamorano JL, Erdine S, Kiowski W, Agabiti-Rosei E, Ambrosioni E, Lindholm LH, Viigimaa M, Adamopoulos S, Agabiti-Rosei E, Ambrosioni E, Bertomeu V, Clement D, Erdine S, Farsang C, Gaita D, Lip G, Mallion JM, Manolis AJ, Nilsson PM, O'Brien E, Ponikowski P, Redon J, Ruschitzka F, Tamargo J, van Zwieten P, Waeber B, Williams B. 2007 Guidelines for the Management of Arterial Hypertension: The Task Force for the Management of Arterial Hypertension of the European Society of Hypertension (ESH) and of the European Society of Cardiology (ESC). J Hypertens 2007; 25 1105-1187.

11 Lawes CM, Rodgers A, Bennett DA, Parag V, Suh I, Ueshima H, MacMahon S. Blood pressure and cardiovascular disease in the Asia Pacific region. J Hypertens 2003; 21 707-716.

12 Romundstad S, Holmen J, Hallan H, Kvenild K, Ellekjaer H. Microalbuminuria and all-cause mortality in treated hypertensive individuals: does sex matter? The Nord-Trondelag Health Study (HUNT), Norway. Circulation 2003; 108: 2783-2789.

13 Giaconi S, Levanti C, Fommei E, Innocenti F, Seghieri G, Palla L, Palombo C, Ghione S. Microalbuminuria and casual and ambulatory blood pressure monitoring in normotensives and in patients with borderline and mild essential hypertension. Am J Hypertens 1989; 2: 259-261.

14 Gerber LM, Shmukler C, Alderman MH. Differences in urinary albumin excretion rate between normotensive and hypertensive, white and nonwhite subjects. Arch Intern Med 1992; 152: 373-377.

15 Parving $\mathrm{HH}$, Mogensen $\mathrm{CE}$, Jensen HA, Evrin PE. Increased urinary albumin-excretion rate in benign essential hypertension. Lancet 1974; 1: 1190-1192.

16 Samuelsson O, Wilhelmsen L, Elmfeldt D, Pennert $\mathrm{K}$, Wedel $\mathrm{H}$, Wikstrand J, Berglund G. Predictors of cardiovascular morbidity in treated hypertension: results from the primary preventive trial in Goteborg, Sweden. J Hypertens 1985; 3 167-176.

17 Lewin A, Blaufox MD, Castle H, Entwisle G, Langford H. Apparent prevalence of curable hypertension in the hypertension detection and follow-up program. Arch Intern Med 1985; 145: 424-427.

18 Bulpitt CJ, Beevers DG, Butler A, Coles EC, Hunt D, Munro-Faure AD, Newson RB, O'Riordan PW, Petrie JC, Rajagopalan B. The survival of treated hypertensive patients and their causes of death: a report from the DHSS hypertensive care computing project (DHCCP). J Hypertens 1986; 4: 93-99.

19 Kannel WB, Stampfer MJ, Castelli WP, Verter J. The prognostic significance of proteinuria: the Framingham study. Am Heart J 1984; 108: 1347-1352.

20 Yudkin JS, Forrest RD, Jackson CA. Microalbuminuria as predictor of vascular disease in non-diabetic subjects. Islington Diabetes Survey. Lancet 1988; 2 530-533.

21 King H, Aubert RE, Herman WH. Global burden of diabetes, 1995-2025: prevalence, numerical estimates, and projections. Diabetes Care 1998; 21 : 1414-1431.

22 Kearney PM, Whelton M, Reynolds K, Muntner P, Whelton PK, He J. Global burden of hypertension: analysis of worldwide data. Lancet 2005; 365: 217-223.

23 Parving HH, Lewis JB, Ravid M, Remuzzi G, Hunsicker LG. Prevalence and risk factors for microalbuminuria in a referred cohort of type II diabetic patients: a global perspective. Kidney Int 2006; 69: 2057-2063.
24 Shi HL, Fang JC, Zhu XX. Prevalence of diabetes mellitus and associated risk factors in an adult urban population in Shanghai. Diabetes Metab 1998; 24: 539-542.

25 Gozzoli V, Palmer AJ, Brandt A, Spinas GA. Economic and clinical impact of alternative disease management strategies for secondary prevention in type 2 diabetes in the Swiss setting. Swiss Med Wkly 2001; 131: 303-310.

26 Woo J, Cockram CS, Swaminathan R, Lau E, Chan A, Cheung R. Microalbuminuria and other cardiovascular risk factors in nondiabetic subjects. Int J Cardiol 1992; 37 345-350.

27 Yamada T, Komatsu M, Komiya I, Miyahara Y, Shima Y, Matsuzaki M, Ishikawa Y, Mita R, Fujiwara M, Furusato N, Nishi K, Aizawa T. Development, progression, and regression of microalbuminuria in Japanese patients with type 2 diabetes under tight glycemic and blood pressure control: the Kashiwa study. Diabetes Care 2005; 28 2733-2738.

28 Buranakitjaroen P, Deerochanawong C, Bunnag P. Microalbuminuria prevalence study (MAPS) in hypertensive patients with type 2 diabetes in Thailand. J Med Assoc Tha 2005; 88: 1624-1629.

29 DU J, Pan CY. [A survey of microalbuminuria prevalence in hypertensive type 2 diabetic patients in mainland China]. Zhonghua Nei Ke Za Zhi 2007; 46: $184-188$.

30 Guan MP, Li CZ, Xue YM, Shen J, Gao F, Luo XR. [Prevalence of microalbuminuria in type 2 diabetic patients with hypertension]. Di Yi Jun Yi Da Xue Xue Bao 2005; 25 234-235.

31 Kong NC, Chia YC, Khalid BA, Juwita S, Samiah Yasmin AK, Yap LY, Norlaila M, Menon J, Tan C, Fung YK. Microalbuminuria prevalence study in hypertensive type 2 diabetic patients in Malaysia. Med J Malaysia 2006; 61: 457-465.

32 Sja'bani M, Asdie AH, Widayati K, Subroto Y, Kariadi SH, Arifin AY, Adhiarta IG, Permana H, Hendromartono T A, Adi S, Wibisono S, Murtiwi S. Microalbuminuria prevalence study in hypertensive patients with type 2 diabetes in Indonesia. Acta Med Indones 2005; 37: 199-204.

33 Weir MR. Albuminuria predicting outcome in diabetes: incidence of microalbuminuria in Asia-Pacific Rim. Kidney Int Supp/ 2004; 92: S38-S39.

34 Wu AY, Tan CB, Eng PH, Tan KT, Lim SC, Tan EK. Microalbuminuria prevalence study in hypertensive patients with type 2 diabetes mellitus in Singapore. Singapore Med $\mathrm{J}$ 2006; 47: 315-320.

35 Yeung VT, Lee KF, Chan SH, Ho LF, Leung SK, Wong HY. MicroAlbuminuria Prevalence Study (MAPS) in hypertensive type 2 diabetic patients in Hong Kong. Hong Kong Med J 2006; 12: 185-190.

36 Chan GC. Type 2 diabetes mellitus with hypertension at primary healthcare leve in Malaysia: are they managed according to guidelines? Singapore Med J 2005; 46: 127-131.

37 Park JY, Kim HK, Chung YE, Kim SW, Hong SK, Lee KU. Incidence and determinants of microalbuminuria in Koreans with type 2 diabetes. Diabetes Care 1998; 21 . 530-534.

38 Coresh J, Selvin E, Stevens LA, Manzi J, Kusek JW, Eggers P, Van Lente F, Levey AS Prevalence of chronic kidney disease in the United States. JAMA 2007; 298: 2038-2047.

39 Hillege HL, Janssen WM, Bak AA, Diercks GF, Grobbee DE, Crijns HJ, van Gilst WH, De Zeeuw D, De Jong PE. Microalbuminuria is common, also in a nondiabetic, nonhypertensive population, and an independent indicator of cardiovascular risk factors and cardiovascular morbidity. J Intern Med 2001; 249: 519-526.

40 Leoncini G, Viazzi F, Rosei EA, Ambrosioni E, Costa FV, Leonetti G, Pessina AC, Trimarco B, Volpe M, Deferrari G, Pontremoli R. Chronic kidney disease in hypertension under specialist care: the I-DEMAND study. J Hypertens 2010; 28: $156-162$

41 Bohm M, Thoenes M, Danchin N, Bramlage P, La Puerta P, Volpe M. Association of cardiovascular risk factors with microalbuminuria in hypertensive individuals: the i-SEARCH global study. J Hypertens 2007; 25: 2317-2324.

42 Cerasola G, Mule G, Cottone S, Nardi E, Cusimano P. Hypertension, microalbuminuria and renal dysfunction: the Renal Dysfunction in Hypertension (REDHY) study. J Nephrol 2008; 21: 368-373.

43 Cerasola G, Mule G, Nardi E, Cusimano P, Palermo A, Arsena R, Guarneri M, Geraci C, Cottone S. Clinical correlates of renal dysfunction in hypertensive patients without cardiovascular complications: the REDHY study. J Hum Hypertens 2010; 24: 44-50.

44 Kim CH, Kim HK, Park JY, Park HS, Hong SK, Park SW, Lee KU. Association of microalbuminuria and atherosclerotic risk factors in non-diabetic subjects in Korea. Diabetes Res Clin Pract 1998; 40: 191-199.

45 National Heart, Lung, and Blood Institute. JNC 7 Express: the seventh report of the joint national committee on prevention, detection, evaluation, and treatment of high blood pressure. National Institute of Health, Bethesda, MD, 2003.

46 Micral Test: an Accu-Check product 2008, Indianapolis, In, Roche Diagnostics Ltd.

47 Annemans L, Demarteau N, Hu S, Lee TJ, Morad Z, Supaporn T, Yang WC, Palmer AJ. An Asian regional analysis of cost-effectiveness of early irbesartan treatment versus conventional antihypertensive, late amlodipine, and late irbesartan treatments in patients with type 2 diabetes, hypertension, and nephropathy. Value Health 2008; 11: 354-364

48 Eknoyan G, Hostetter T, Bakris GL, Hebert L, Levey AS, Parving HH, Steffes MW, Toto R. Proteinuria and other markers of chronic kidney disease: a position statement of the national kidney foundation (NKF) and the national institute of diabetes and digestive and kidney diseases (NIDDK). Am J Kidney Dis 2003; 42: 617-622.

49 Jensen JS. Intra-individual variation of overnight urinary albumin excretion in clinically healthy middle-aged individuals. Clin Chim Acta 1995; 243: 95-99. 
50 Zelmanovitz T, Gross JL, Oliveira JR, Paggi A, Tatsch M, Azevedo MJ. The receiver operating characteristics curve in the evaluation of a random urine specimen as a screening test for diabetic nephropathy. Diabetes Care 1997; 20: 516-519.

51 Arnlov J, Evans JC, Meigs JB, Wang TJ, Fox CS, Levy D, Benjamin EJ, D'Agostino RB, Vasan RS. Low-grade albuminuria and incidence of cardiovascular disease events in nonhypertensive and nondiabetic individuals: the Framingham Heart Study. Circulation 2005; 112: 969-975.

52 Gerstein HC, Mann JF, Yi Q, Zinman B, Dinneen SF, Hoogwerf B, Halle JP, Young J, Rashkow A, Joyce C, Nawaz S, Yusuf S. Albuminuria and risk of cardiovascular events, death, and heart failure in diabetic and nondiabetic individuals. JAMA 2001; 286: 421-426.

53 Hillege HL, Fidler V, Diercks GF, van Gilst WH, De Zeeuw D, van Veldhuisen DJ, Gans RO, Janssen WM, Grobbee DE, De Jong PE. Urinary albumin excretion predicts cardiovascular and noncardiovascular mortality in general population. Circulation 2002; 106: 1777-1782.

54 Klausen K, Borch-Johnsen K, Feldt-Rasmussen B, Jensen G, Clausen P, Scharling $H$, Appleyard M, Jensen JS. Very low levels of microalbuminuria are associated with increased risk of coronary heart disease and death independently of renal function, hypertension, and diabetes. Circulation 2004; 110: 32-35.

55 Cerasola G, Cottone S, Mule G, Nardi E, Mangano MT, Andronico G, Contorno A, Li VM, Galione P, Renda F, Piazza G, Volpe V, Lisi A, Ferrara L, Panepinto N, Riccobene R. Microalbuminuria, renal dysfunction and cardiovascular complication in essential hypertension. J Hypertens 1996; 14: 915-920.

56 Hsu CC, Brancati FL, Astor BC, Kao WH, Steffes MW, Folsom AR, Coresh J. Blood pressure, atherosclerosis, and albuminuria in 10113 participants in the atherosclerosis risk in communities study. J Hypertens 2009; 27: 397-409. 